\title{
Architecture et art dans les Balkans pendant la période ottomane
}

Architecture and Art in the Balkans During the Ottoman Times

\section{Alkis Prépis}

\section{(2) OpenEdition}

\section{Journals}

Édition électronique

URL : http://journals.openedition.org/etudesbalkaniques/319

ISSN : 2102-5525

\section{Éditeur}

Association Pierre Belon

\section{Édition imprimée}

Date de publication : 1 janvier 2005

Pagination : 85-128

ISBN : 2-910860-05-1

ISSN : $1260-2116$

\section{Référence électronique}

Alkis Prépis, « Architecture et art dans les Balkans pendant la période ottomane », Études balkaniques [En ligne], 12 | 2005, mis en ligne le 07 avril 2009, consulté le 20 avril 2019. URL : http:// journals.openedition.org/etudesbalkaniques/319

Ce document a été généré automatiquement le 20 avril 2019

Tous droits réservés 


\title{
Architecture et art dans les Balkans pendant la période ottomane
}

\author{
Architecture and Art in the Balkans During the Ottoman Times
}

\section{Alkis Prépis}

1 Après un demi-siècle d'adhésion quasi dogmatique de la majorité des historiens des pays balkaniques au modèle "destructif» de la conquête des Balkans, d'après lequel les Ottomans n'auraient laissé sur leur passage que des cendres et des ruines, cette image a été sensiblement modifiée. Cette évolution est due aux importants travaux de certains historiens qui ont étudié plus objectivement et en profondeur des données anciennes ou nouvelles, provenant surtout des archives ottomanes, mais aussi à l'examen approfondi des monuments eux-mêmes. De ce fait, la réalité apparaît donc beaucoup plus complexe par rapport au modèle précédent, trop généralisateur et simpliste.

2 Après la conquête, le peuple, d'abord effrayé par la nouvelle réalité ottomane, n'a pas tardé, pourtant, à s'y adapter en s'appuyant naturellement sur ses valeurs culturelles traditionnelles. Seule institution représentant désormais le peuple conquis, l'Église orthodoxe, a de facto été chargée de cette tâche.

3 Les rayas ${ }^{1}$, sujets non musulmans ou « infidèles », constituaient la grande majorité de la population. La religion, en termes de dogme ou même d'appartenance -comme on le saitconstituait traditionnellement l'élément principal d'identification collective dans l'État ottoman; les différentes communautés des rayas ont été divisées en trois millet, correspondant aux principales religions des sujets non musulmans: orthodoxes, arméniens et juifs, chacun ayant son chef, appelé millet başı. Le plus grand millet était le milletrum, c'est-à-dire orthodoxe. Son chef, désigné par Mehmed II en personne, fut un moine et théologien renommé Gennadios (Georgios Scholarios), opposant farouche au Concile de Florence de 1439, où avait été décidée la réunion de l'Église orthodoxe avec l'Église catholique. Outre les affaires ecclésiastiques, celles qui relevaient du droit canon et celles qui concernaient les sujets chrétiens étaient également du ressort du patriarche de Constantinople. De cette manière, l'Église s'est érigée en grande puissance dans l'Empire et l'efficacité de l'administration ecclésiastique était, à côté du pouvoir ottoman, 
un facteur décisif pour le sort des chrétiens dans les Balkans. Le chef de la Grande Église parvient, en 1766-7, à étendre sa juridiction à tous les orthodoxes des Balkans. Il existait, jusqu'alors, deux entités autocéphales représentant les églises orthodoxes dans lesquelles la messe était célébrée en langue slave ecclésiastique : l'archevêché d'Ohrid (Lychnidos, dont la juridiction s'étendait sur une grande partie de la Macédoine et en Albanie du Centre et du Nord) et l'archevêché d'Ipek (Peć, ayant dans sa juridiction les orthodoxes de Serbie et de Bosnie-Herzégovine). Ces instances étaient les symboles de l'identité « ethnique » des Bulgares et des Serbes, bien que sur le plan du dogme ils n'aient pas eu de divergences théologiques avec Constantinople. Mais la notion de représentation "ethnique " rendait la décision de faire dépendre les Églises slaves du patriarcat œcuménique extrêmement grave; elle ne manquerait pas d'engendrer de graves problèmes au cours du XIX ${ }^{e}$ siècle, au moment de l'émergence de la conscience nationale des peuples balkaniques avant la création finale de deux patriarcats séparés. La cohésion ethnique et religieuse du millet des Arméniens, appartenant au dogme monophysite, était beaucoup moins développée. Le millet juif, enfin, ne fut reconnu officiellement qu'en 1839, bien qu'il eût fonctionné régulièrement depuis 1453. Les Juifs sépharades, qui avaient émigré d'Espagne à Istanbul et dans les Balkans, en constituaient le groupe le plus important.

Le trait principal de l'art qui prend forme sous l'influence directe de l'Église orthodoxe est le conservatisme, le front religieux officiel s'exprimant en réaction non seulement contre l'Islam hétérodoxe, mais aussi contre l'Église catholique et tout ce que celle-ci représentait. Cela explique le besoin, fréquemment éprouvé, de revisiter les modèles byzantins que nous allons rencontrer au cours de notre analyse.

\section{Panorama général}

Dans les Balkans, la nouvelle réalité correspond aux buts stratégiques du pouvoir ottoman et reflète sa géopolitique. Des villes médiévales constituant des carrefours dans le réseau routier commercial ou des centres de production, de collecte ou d'élaboration des produits de l'arrière-pays seront renforcés, tout en conservant leur place (par exemple les centres métropolitains d'Andrinople et de Philippopolis, où une grande partie de la population chrétienne indigène a trouvé refuge). Certes, des changements considérables se sont produits dans la composition ethnique de la population des centres urbains. Les chrétiens se voient privés de leur pouvoir administratif et contraints à subir le poids de l'organisation centralisatrice militaro-religieuse de l'Empire ottoman; cependant l'élément non musulman se maintient dans les villes et souvent même dans une proportion plus élevée que l'élément musulman. Il a pu ainsi assurer un rôle de gardien et de vecteur de certaines traditions urbaines et jouer un rôle actif dans les processus productifs dans la ville.

6 Lors de l'occupation des villes, les conquérants suivaient, dans l'ensemble, la loi de la guerre sainte: les villes qui avaient essayé de résister subissaient le pillage et la population indigène était réduite en esclavage. En revanche, si des villes ou des régions entières, dirigées précédemment par des chefs locaux, décidaient de capituler, le traitement des chrétiens et de leurs lieux de culte était différent : ils gardaient euxmêmes la possession de leurs églises². 
Conformément au şeriat, base de la loi islamique comprenant notamment le Coran et les hadiths, les sujets "infidèles» étaient privés du droit de construire de nouvelles fondations de culte. L'utilisation des cloches et la construction de clochers étaient interdites à l'exception, pourtant, des régions dans lesquelles les chrétiens s'étaient assuré un régime spécial, comme les îles de la mer Égée et le Mont-Athos. Toutefois, contrôler l'interprétation de la loi n'était pas toujours possible ou ne se faisait pas toujours de manière rigoureuse. Ainsi, au XVI ${ }^{e}$ siècle, les privilèges d'antan de certains monastères ont été renouvelés et il a même été permis de reconstruire d'anciennes églises dans leurs dimensions précédentes. En 1774, en vertu du traité de KüçükKaynarca, conclu entre la Russie et l'État ottoman, la protection des églises chrétiennes du territoire ottoman est devenue effective. Par le traité d'Andrinople (1829) qui marque la fin de la guerre russo-turque, les chrétiens se voient accorder le droit de construire de nouvelles églises en pierre de taille à la place des anciennes églises en bois ou encore de restaurer les anciennes "sans élévation ni élargissement». Enfin, aux termes du Hatti Humayun de 1856, promettant la liberté religieuse et la protection des sujets nonmusulmans, le projet de nouvelles églises était soumis directement à la Porte, qui donnait aussitôt son approbation par un firman.

8 En général, dans les grandes villes, surtout celles qui ont bénéficié d'une tradition byzantine continue comme Andrinople, Salonique, Kastoria, Sofia, Philippopolis, il n'y a que peu de nouvelles églises ou monastères, et de peu d'importance du point de vue architectural. Dans d'autres régions, en revanche (en Attique ou en Épire), on construit par dizaines de nouveaux édifices, le plus souvent des églises de monastères, phénomène qui s'explique soit par la faible présence des populations musulmanes, soit par des raisons de tolérance religieuse. Généralement, dans les grands centres urbains, on a autorisé la population chrétienne locale à conserver ses églises, mais pas les plus importantes. La destruction ou la transformation de certaines églises en mosquées traduit, en fait, une stratégie politique visant à imposer et à souligner de manière symbolique la religion officielle de l'État, l'islam. C'est pourquoi des églises byzantines de grande importance et de grande valeur historique sont transformées en mosquées: Sainte-Sophie à Istanbul, Saint-Georges à Salonique, Sainte-Sophie et Saint-Georges à Sofia, l'église métropolitaine de Sainte-Sophie à Andrinople ${ }^{3}$. D'autres églises sont détruites et sur leurs ruines sont édifiées des mosquées : dans l'archevêché d'Ohrid, qui fut pendant des siècles le cœur de la chrétienté slave, l'église métropolitaine byzantine détruite a été remplacée par une mosquée. L'église principale du petit monastère de Saint-Pantéléimon, fondé par saint Clément non loin du lac d'Ohrid et qui contenait les reliques du saint, fut détruite par Mehmed II et sur son emplacement on construisit la mosquée Imaret. Dans certains cas, cette politique a été poursuivie pendant les siècles suivants. En règle générale, donc, les nouvelles églises métropolitaines orthodoxes des grandes villes ont perdu leur importance, soit parce qu'elles ont été remplacées par des églises périphériques, soit parce qu'on en a construit de nouvelles, considérablement plus petites et plus éloignées du centre. Le «remaniement » ottoman de la ville balkanique médiévale impliquait des approches complètement différentes et a modifié l'importance que des monuments religieux orthodoxes avaient précédemment dans l'espace urbain.

Dans l'arrière-pays des zones de plaine les églises paroissiales sont construites à l'écart du centre du village, dans les cours situées entre les maisons, cachées derrières de grands enclos. Il s'agit de constructions d'une maçonnerie grossière ou de hourdis en bois remplis de pierres qui ne se distinguent guère des habitations rurales ordinaires -on a 
souvent considéré en fait cette ressemblance comme délibérée-, avec une toiture basse en bois, le plus fréquemment recouverte de plaques d'ardoise. Ces églises sont dépourvues de clocher ou de coupole et dans l'intérieur obscur l'éclairage rudimentaire est assuré par des lucarnes. La partie centrale de l'église comprend une seule pièce souterraine, destinée aux hommes, alors que le gynécée se trouve à un autre niveau, avec une entrée séparée, isolé de la partie centrale de l'église par une cloison en bois : la règle de la séparation complète des sexes sera appliquée, sans exception, tout au long de la période ottomane, dans toute la péninsule balkanique, même dans les régions qui se trouvent sous domination vénitienne. L'iconostase est d'une facture archaïque, d'une forme et d'une typologie rudimentaires. Dans les églises les plus anciennes, les fresques font défaut, alors que les icônes sont peu nombreuses et d'un style dépouillé.

Pendant les premiers siècles de la domination ottomane, les plus difficiles, les régions montagneuses, à l'écart des routes très fréquentées et loin du contrôle direct de l'administration, avaient acquis plus d'importance; le centre de gravité de la vie économique et culturelle des rayas a été en fait déplacé vers ces régions. Les privilèges accordés au niveau local par le biais d'une série de mécanismes de l'État ottoman ${ }^{4}$ ont contribué au développement du commerce et de l'artisanat, entraînant l'émergence d'une classe privilégiée qui, dans certaines provinces et régions éloignées, avait la possibilité de financer la construction et la décoration murale de petites et modestes églises au début, et plus tard, à partir de la fin du XVII siècle, de grands et imposants bâtiments. C'est par exemple le cas d'Arbanassi, village de la Bulgarie du Nord, où grâce aux privilèges accordés par les Ottomans aux étrangers Arvanito-valaques l'église de la Nativité (1597, fresques de 1632 et 1649) et celle des Archanges Michel et Gabriel (fin XVI ${ }^{\mathrm{e}}$ - début XVII siècle) ont été construites. En même temps, le fait que le Patriarcat avait le droit d'accorder des privilèges et des immunités aux communautés monastiques ( $\sigma \tau \alpha \nu \rho \circ \pi \eta ́ \gamma l \alpha)^{5}$ avait comme conséquence l'accès à une indépendance et le développement d'un art à travers lequel s'est également exprimée l'Église officielle.

\section{$\mathrm{XVI}$-XVII siècles : résistances, médiations et adaptations}

11 Pendant les deux premiers siècles de la domination ottomane (fin $\mathrm{XV}^{\mathrm{e}}$-troisième quart du $\mathrm{XVII}^{\mathrm{e}}$ siècle), considérés comme les plus durs et les plus obscurs, c'est au sein de fondations monastiques que se déploie l'essentiel de l'activité de construction. En effet, cette période est considérée comme la plus brillante de l'architecture monastique postbyzantine pour tout l'espace balkanique. Les nouvelles conditions de paix, régnant surtout durant le $\mathrm{XVI}^{\mathrm{e}}$ siècle, ont donné l'occasion de rénover plusieurs monastères anciens alors que des monastères récemment fondés ont connu un épanouissement spectaculaire. On y retrouve le plus souvent la reprise des types d'anciens monastères qui servent de modèle, comme, par exemple, celui de Lavra et de Chilandari sur le MontAthos, celui de Saint-Jean avec la grotte de l'Apocalypse à Patmos, celui de la Néa Moni à Chio. Ce dernier facteur a largement contribué à l'établissement d'une continuité avec le passé byzantin, au moyen de la répétition, à une grande échelle, des types et des formes, phénomène constaté en général dans toute la partie continentale de la péninsule.

En effet, l'architecture monastique de cette période ne se distingue de celle de la période byzantine ni sur le plan de la conception ni sur celui de la fonction. Les grands ensembles 
monastiques, tout comme les petits, ont généralement suivi les traits de l'architecture du Mont-Athos, marquée par son caractère prononcé de forteresse. Le type architectural prédominant dans les églises monastiques les plus importantes de cette période, est appelé athonikos ou hagioritikos (du Mont-Athos ou de la Sainte-Montagne) : le modèle bien connu de l'église en croix inscrite, marqué par des conques latérales développées destinées au chœur des chantres au nord et au sud, avec des arcades extérieures et un large narthex à piliers. En règle générale, la partie centrale est couverte d'une coupole à haut tambour. On peut y relever plusieurs qualités de l'architecture byzantine: maçonneries soignées, échelonnement équilibré des volumes, linéarité dans la composition et recherche de la polychromie. Dans les zones proches de sites archéologiques les murs sont parés de marbres anciens ou de restes byzantins. Les surfaces extérieures sont rehaussées de rubans ciselés, d'arcs aveugles ou de niveaux d'assises de briques. L'emploi de céramiques de l'Asie Mineure -plats ou assiettes incrustés dans les surfaces extérieures- est considéré comme une des rares influences de l'art oriental. D'autre part, l'idée des conques latérales pour le chœur a immédiatement influencé des églises de plus petite taille (petits monastères du Pinde, églises bulgares, églises principales des monastères à Fruška Gora entre Save et Danube).

La décoration intérieure est assez riche. Même si les matériaux sont en général modestes (bois, revêtements, sols de galets) très souvent l'habileté des maîtres ouvriers en fait de véritables chefs-d'œuvre: iconostases richement décorées, sièges "despotiques", ambons, coffres, pupitres, voiles brodés de la Sainte Table. Comme pendant la période byzantine, les murs des églises ont constitué durant la période ottomane un grand livre didactique exerçant une influence directe sur l'esprit des croyants. L'architecture des églises de cette période n'est pas simplement un vecteur de cette idéologie exprimée de manière artistique, mais elle en est partie intégrante. La pensée théologique, en mettant de côté une grande partie du dogme, s'adapte alors au mode de pensée du peuple et prend un style directement didactique, de caractère primitif certes mais très vif et très réaliste. Les cycles iconographiques traditionnels s'enrichissent de divers éléments du style populaire qui les rendent facilement compréhensibles par les fidèles. Dans la peinture murale et celle des icônes le style monumental de la période précédente est en régression, alors que se multiplient les sujets qui tantôt font l'éloge de la foi chrétienne indomptée des martyrs et des néo-martyrs ${ }^{6}$, tantôt soulignent la présence protectrice des saints guerriers, tantôt jettent aux tortures de l'enfer les pécheurs, les infidèles, les hétérodoxes et les hérétiques ${ }^{7}$, tout en mettant l'accent sur la sagesse des grands prélats, piliers de l'Église orthodoxe.

On sait que ce sont les mêmes esnaf ${ }^{8}$ d'artisans qui en se déplaçant, construisaient et décoraient les édifices publics ottomans, les bâtiments religieux (mosquées, églises chrétiennes, synagogues) et les domiciles privés des archontes. Certains éléments révèlent l'influence de l'architecture laïque sur des édifices religieux, tant sur le plan de la construction que celui de la décoration, peinte ou sculptée, qu'elle soit en bois ou en pierre. Ainsi, l'emploi des voûtes aveugles dans certaines églises ou celui des trompes d'angles portant des pendentifs pour le recouvrement de l'espace central, des parties d'angle ou des arcades extérieures, est considéré comme dénotant une influence des modèles de l'architecture ottomane ${ }^{9}$.

15 De 1514 à 1568 sont construits en Grèce du Nord les grands et importants monastères du Mont-Athos: Iviron, Dionysiou, Koutloumousiou, Philothéou, Stavronikita, Xénophontos et Docheiariou; en Grèce centrale, les églises principales des monastères des Météores, 
dans un site naturel impressionnant : le Grand Météore (1545), la Trinité (1476), Varlaam (1517) et Saint-Stéphane (1536), Roussanou (1560) ; toujours en Thessalie, le monastère de Mégalon Pylon-Dousiko (1558), le Monastère de Pétra au Pinde (1550), de SaintPantéléimon d'Aghia (1580), le monastère de Phlamourion sur le Pilion (1602), le monastère d'Antinitsa (fin XVe s.) et le monastère de Galataki en Eubée (1547). Tous ces monuments sont d'une architecture exceptionnelle, avec une décoration murale excellente, des iconostases et des pupitres sculptés en bois recouvert d'or, des icônes précieuses qui traduisent nettement l'influence du Mont-Athos. Cette architecture est accompagnée d'importantes constructions fonctionnelles, réfectoires, cellules, ateliers, cuisines, hôpitaux. Des églises de petite taille, mais richement décorées sont typiques de l'architecture épirote (monastères de Philanthropinon et du Prodrome dans l'île du lac de Ioannina, monastère de Sosinou) et d'Albanie du Sud (églises des monastères de SaintJean-Prodrome à Sipisha de Moschopolis-Voskopojë (1632), de Saint-Nicolas à Saraqinisht (1630) ou de l'Assomption à Zervat (1569), à Delvinë (1580) et à Vlahogoranxi (1662).

En Bulgarie le monastère de Rila (1460) est reconstitué et les reliques de son patron saint Ivan y sont transférées de Tirnovo, alors que des fresques sont réalisées au monastère de Dragalevsky (1476). Au centre de la péninsule balkanique, la «dernière école macédonienne " poursuit son activité centrée notamment sur les fresques de l'église primitive du monastère de la Transfiguration des Météores (1483). Il s'agit des monastères de Boboševo (1488), Orlića (1491) et Kremikovsky (1498) en Bulgarie, du monastère de Poganovo (1500, avec une influence de l'art italien de la Renaissance, en République de Macédoine, et de Balinešti (1493) en Roumanie. Dans un des plus anciens ensembles de peintures murales, à Patrăut (1487), on ne trouve que des inscriptions en grec. Des échos de l'atelier macédonien survivent à Dorohoi (1522) et à Hirlaŭ (1530).

Le nouvel élan des monastères a conduit à ranimer des ensembles byzantins désertés, comme celui de Saint-Jean-Prodrome à Serrès ou d'Hosios-Loukas en Phocide. En Bulgarie, on voit la restauration du monastère de Rožen (1532) près de Méléniko, de Kurlikovo (1596), de Sainte-Paraskévi à Voukovo (1598), de Saint-Stéphane à Mésimvria (Nessebar, 1599) ainsi que la reconstitution du monastère de la Panagia Petritsonissa (1604) à Bačkovo, près de la citadelle de Sténimachos (Assenovgrad). Selon la remarque d'André Grabar : « la Turcocratie y signifia le retour de l'art proprement grec (Tirnovo, Arbanassi, Bačkovo) dans ce que fut la Bulgarie médiévale $»^{10}$. En République de Macédoine on fait restaurer le monastère des Saints-Archanges près de Skopje, tandis que se développent des écoles philologiques dans les monastères de Treskaveć, Jeglovski et Mateić. En Albanie, Onoufrios originaire de Berat (Saints-Apôtres de Kastoria, 1547, Sainte-Paraskévi, à Balsh, 1554) est le représentant d'un art soigné, caractérisé par sa finesse et son éclectisme ; les influences occidentales n'y manquent pas.

L'école connue sous le nom d'école de la Morava est constituée par le groupe d'églises construites par les princes serbes qui, bien que vassaux des Turcs, à la suite de la bataille de Kosovo Polje (1389), maintiennent leur puissance économique. Le prestige du MontAthos, qui attire vivement leur intérêt, reste si grand que le type de l'église à trois conques prend un caractère quasi obligatoire, alors que la construction sera révisée sur la base des traits saillants de Gračanića. A Ravanića (1375), on a bâti une église à cinq coupoles sur quatre piliers libres, en maçonnerie byzantine, mais aussi plusieurs éléments décoratifs. La Lazarića à Kruševac (1377), dotée d'une ornementation plus riche (des complexes de nœuds, des rosettes, des animaux imaginaires) est une église à vaisseau unique, dont le narthex est surmonté d'un grand clocher. On rencontre les mêmes 
caractéristiques à Ljouboštinja, à Naupara (1377-1382) et à Kalenić (début du XVe siècle). A Resava (Manasija, 1406-18) on retrouve la construction de Ravanića, mais avec une maçonnerie plate, cette fois, et de petites arcades, caractéristiques des maçons de la région de Zadar en Dalmatie. L'école va étendre ses constructions dans les régions proches du Danube (Remeta, Krušedol, Novo Hopovo), mais on constate un tournant conservateur en direction du style médiéval de Raška (Mlado Nagoričino). Au Kosovo, l'église patriarcale de Peć et les monastères renommés de Dečani et de Gračanića restent d'abord intacts pour être ensuite pillés. Après la conquête ottomane, le Patriarcat de Peć a cessé de fonctionner et les provinces serbes sont mises sous la juridiction de l'archevêché d'Ohrid. La reconstitution du Patriarcat de Peć, en 1557, fut un événement de grande importance historique pour la nation serbe ${ }^{11}$. Cette renaissance intellectuelle se reflète dans la restauration des églises et des monastères en ruines. Ne serait-ce qu'au Kosovo et dans la Metohija, une vingtaine d'églises environ a été construite, comprenant aussi des imprimeries, dont la plus importante a été fondée au monastère de Gračanica, en 1539. Le patriarche serbe Makarie Sokolović en personne a dirigé et financé la restauration de certains des plus importants monastères serbes, à Peć (1561), Budisavci (1568), Studenica (1568), Gračanica (1570), Banja Pribojska (1571). La même tendance se remarque dans le répertoire iconographique. Le Patriarcat serbe a fait revivre et a introduit de nouveaux cultes de princes médiévaux, d'archevêques, de martyrs de la foi et de saints guerriers, en particulier à travers le cycle des Nemanides.

ure une transformation lente et progressive de sa tradition culturelle et religieuse sous l'influence vénitienne. Sur le littoral dalmate, l'influence mixte du Roman et du Gothique, arrivée par l'intermédiaire des moines franciscains, se maintient dans le cadre des traditions locales. Les artisans de Kotor (maçons, tailleurs de pierre, sculpteurs, graveurs, peintres) ont relevé le défi lancé non seulement par Dubrovnik, Split et Zadar, mais aussi par les villes italiennes, restant cependant toujours fidèles aux particularités de leur style local avec un florilège de traits architecturaux et de formes romanes, byzantines et de l'école de Raška. Au XV siècle, dans les villes dalmates du Monténégro les formes architecturales et la décoration de la Renaissance s'imposent. Elles vont notamment se développer après 1530 , avec la contribution d'architectes et de peintres italiens. Le reste du pays s'efforce de conserver la tradition religieuse (dans l'architecture, la sculpture, l'iconographie), tout en restant ouvert aux nouvelles tendances et en servant, de surcroît, d'intermédiaire vers le reste de la péninsule. Ainsi, dans le monastère médiéval de Moraća (1252), le peintre serbe Georgije Mitrofanović, venu de Chilandari, va ressusciter la tradition de la peinture murale byzantine dans un style personnel (1616), alors que pour la décoration sculptée en bois on adoptera un style mixte, sanctionnant la cohabitation des nouvelles tendances de la Renaissance et la tradition byzantine (pupitres: 1645, 1714). Le monastère de Dobrilovina (1609) à Tara fut calqué sur celui de Morača. L'église principale du monastère de Plevlje fut reconstruite dans les années 1540 , tandis qu'en 1592 on y ajouta un large narthex à coupole. L'église principale du monastère de Piva fut reconstruite en 1573 par l'archevêque d'Herzégovine dans des dimensions beaucoup plus importantes que celles de l'église initiale, détruite, et des peintres grecs en réalisèrent la décoration murale.

Comme l'a écrit André Grabar, «la Moldavie a connu l'esthétique byzantine par laquelle elle fut séduite, après la chute de Constantinople $»^{12}$. en 1517 selon le type de l'édifice à trois conques absidiales, avec un narthex développé, 
dans le style athonite. L'espace principal est surmonté de deux coupoles surhaussées caractéristiques ; deux autres, plus petites, d'une forme irrégulière, couvrent les parties angulaires du narthex, alors que les façades sont marquées par l'horizontale d'une longue corniche torsadée. Les principautés de Valachie et de Moldavie ont eu la chance d'avoir une autonomie relative assurant le développement du style de l'école moldave. Le type primitif de l'école apparaît à Voroneț (1488); un grand narthex rectangulaire, couvert d'une voûte en plein cintre, un vaisseau central à trois conques absidiales avec une coupole exhaussée, et deux arcs-boutants extérieurs de part et d'autre de la conque orientale. Dans les monastères de Neamt (1497) et de Suceava (1522) l'église a été rallongée par l'ajout d'un narthex extérieur, alors qu'une chapelle funéraire s'interpose entre le narthex et la partie centrale de l'église. Les parties secondaires sont couvertes de voûtes aveugles, et placées sous un toit commun à forte pente faisant largement saillie sur le vaisseau central. Ces caractéristiques vont se développer amplement au cours du $\mathrm{XVI}{ }^{e}$ siècle. Les églises de Moldavie constituent un groupe de monuments cohérent et unique, marquant une évolution importante de l'art religieux dans les Balkans: le développement d'une décoration importante sur les murs extérieurs des cathédrales de Patrauti (1487), Suceava (fresques de 1534), Probota (1531-3), Homor (1530), Moldovị̧a (1532, fresques de 1537), Arbore (1503, fresques de 1541), VoroneŢ (peinture murale: 1488, 1496, ajout du narthex: 1547, fresques de 1552), Suceviţa (environ 1602-4). On remarquera des œuvres gigantesques et complexes, comme la Seconde Parousie du Messie, dans la partie occidentale de l'église de VoroneŢ, l'Arbre de Jessé (comprenant les philosophes grecs de l'Antiquité) dans la partie méridionale de SuceviŢa, l'Échelle céleste, dans la partie septentrionale de Suceava, témoignant de l'apogée d'une tendance inhérente à la tradition byzantine: l'architecture est soumise à la peinture; l'église entière, à l'intérieur comme à l'extérieur, n'est qu'une surface, un énorme support destiné à la peinture et à l'affirmation du dogme de l'orthodoxie ${ }^{13}$. D'autre part, les hautes iconostases de bois sculpté en bas-relief vont directement contribuer à l'élaboration du style postérieur, appelé « Brancovan », qui se répandra à la fin du XVII et tout au long du XVIII ${ }^{\mathrm{e}}$ siècle dans toute la Valachie.

Depuis la fin du $\mathrm{XVI}^{\mathrm{e}}$ siècle, des moines franciscains, dominicains, jésuites et capucins déploient un prosélytisme intense à Péra, à Istanbul, et dans les îles de Rhodes et de Chio (où la domination franque venait juste, en 1522 et 1566, de prendre fin). L'existence de deux communautés chrétiennes, les mariages mixtes ont conduit dans les îles à la création d'un nouveau type d'église à deux nefs où cohabitent les dogmes orthodoxe et catholique. À Rhodes et dans le Dodécanèse persistent les influences gothiques tardives issues de la présence des chevaliers de Saint-Jean de Jérusalem. Les constructions en pierre de taille, les voûtes d'ogives sont attestées jusqu'à la période ottomane tardive. Les habitants des Cyclades, influencés par la longue présence franque, qui avait rapproché catholiques et orthodoxes dans le même contexte religieux et politique, vivent en coexistence pacifique. Le style architectural des églises est considérablement différent de celui de la Grèce continentale : on y construit plusieurs petites chapelles privées et des monastères très peu peuplés, suivant la tradition byzantine.

La Crète, conquise par les Turcs en 1669, avait vu pendant la domination vénitienne la montée en puissance d'une aristocratie et d'une classe moyenne gréco-vénitienne. Séduite par l'art byzantin tardif, cette clientèle a contribué à son essor, même quand la maniera italienne a commencé à percer dans le style et dans l'iconographie. L'art de l'icône portative et de l'iconostase a été cultivé par des peintres et des sculpteurs; 
l'organisation rendait possible une grande production et une exportation systématique, faisant ainsi de la Crète aux $\mathrm{XV}^{\mathrm{e}}$ et $\mathrm{XVI}^{\mathrm{e}}$ siècles le plus important centre culturel du monde orthodoxe.

Dans les régions des Balkans placées sous domination vénitienne, l'architecture des églises a suivi un cours complètement différent de celui des régions qui se trouvaient sous domination ottomane. Les principes et les formes architecturales de la Renaissance, mais aussi du maniérisme et du baroque ont été très tôt répandus dans ces provinces et ont complètement écarté les anciennes pratiques byzantines. Les maçons comme les sculpteurs, organisés dans des corporations de type urbain, connaissaient et utilisaient des systèmes de référence vénitiens. Ainsi, en Crète aux XVI ${ }^{e}$ et XVII ${ }^{e}$ siècles on a retenu, dans les églises à un ou deux vaisseaux des modèles de Sebastiano Serlio et d'Andrea Palladio, connus par leurs livres, très répandus à l'époque en Italie : le monastère d'Arcadi (1587), le monastère de Gouvernetou (1537), celui de Tzagarolon (1631) ou l'église catholique de Saint-Roch à La Canée (1630). Le même style architectural sera suivi dans les Iles ioniennes sous domination vénitienne. Ainsi à Zakynthos, les basiliques à trois nefs de la Trinité (début XVIe siècle), de la Panagia Phanéroméni (1659), de la Kyria ton Aggelon (1687) et, à Cephalonie l'église à nef unique de la Panagia stous Roggous.

Les peintres crétois, jouissant d'une large clientèle du point de vue géographique, religieux et ethnique, se caractérisent par une habileté, un éclectisme qui oscillent entre l'art italien des XIV $-\mathrm{XV}^{\mathrm{e}}$ siècles et la phase tardive de l'art des Paléologues. Tel est le cas d'Andrea Rico, Andrea Ravia, Nicolao Zafuri. Un élément décisif pour le développement de l'art dans les Balkans du Sud fut la constitution de la communauté des grecs orthodoxes de Venise (1498), après la modification des conditions de séjour accordée par les Vénitiens dans un esprit de tolérance religieuse. L'importante communauté grecque, tout comme le marché culturel de Venise, constituent un pôle d'attraction pour les Crétois et d'autres peintres grecs. Au XVI ${ }^{\mathrm{e}}$ siècle, Dominikos Théotokopoulos -El Grecova suivre ce courant. Plusieurs peintres crétois (parmi les plus importants citons Mihail Damaskinos, Viktorès, Markos Strelitzas Bathas, Thomas Bathas, Emmanouèl Tzanfournaris) exécutent des commandes, approvisionnant en icônes non seulement Venise, mais également les églises métropolitaines catholiques d'autres régions sous domination vénitienne, aussi bien que les monastères du Mont-Athos, du Sinaï, de Patmos, d'Hosios-Loukas ${ }^{14}$. Aux XVI ${ }^{\mathrm{e}}$ et $\mathrm{XVII}^{\mathrm{e}}$ siècles, se créent à Venise des ateliers d'hagiographes grecs qui travaillent pour leur clientèle dans les deux styles, l'orthodoxe traditionnel « alla greca » et l'occidental « all'italiana ».

L'influence occidentale est aussi à l'origine des iconostases en bois sculpté dont l'emploi se généralise dans les églises après la conquête ottomane. L'ancienne clôture byzantine à pilastres et parements de marbre est remplacée par une cloison en bois et complétée par de nouveaux éléments, comme la croix en bois sculpté portant le Christ crucifié flanquée de la Mère de Dieu et de Saint-Jean, ou encore les grandes icônes «despotiques » dans l'intervalle des colonnes. L'habitude de cette haute cloison décorée d'icônes, séparant la nef du sanctuaire constitue à cette époque dans la région l'élément distinctif entre une église orthodoxe et une église catholique, indépendamment de leur forme extérieure ${ }^{15}$. L'usage de l'iconostase en bois s'est généralisé très tôt en Crète et dans les Iles ioniennes d'où il a été introduit, au XVII ${ }^{\mathrm{e}}$ siècle, en Épire et au Mont-Athos. Il faut souligner ici l'influence indirecte exercée, surtout sur l'iconographie mais aussi sur la décoration en bois sculpté des iconostases, non seulement par les icônes mais aussi par les cadres transportés en Dalmatie ou construits sur place. Les artisans crétois ont, ici aussi, joué un 
rôle décisif. Une autre médiation importante est due à l'illustration des livres liturgiques slaves, imprimés à Venise aux XVI ${ }^{\mathrm{e}}$ et XVII ${ }^{\mathrm{e}}$ siècles, avec la collaboration des Grecs. Ces livres furent la source principale de modèles des peintres et des orfèvres de Serbie et d'Herzégovine.

A partir du XVII e siècle, à l'exception de la Sainte-Montagne où il resta le principal représentant de l'architecture officielle pendant toute la période ottomane, le type athonite commence à subir une série de transformations d'échelle et de volume. Les formes habituelles des coupoles, naguère apparentes au-dessus des toitures des églises, sont couvertes par un toit commun avec de petits retranchements sur les côtés étroits. D'habitude, seule la coupole centrale fait saillie, et dans de rares cas, d'autres coupoles apparaissent au-dessus de la partie centrale de l'église. En outre, dans les Balkans du Sud, la diminution des dimensions se conjugue avec la disparition des chapelles, l'utilisation de matériaux modestes, le rétrécissement des coupoles. L'absence de l'aspect imposant et majestueux de la période précédente est évidente. Dans ces circonstances, le goût des monastères du Mont-Athos pour la reproduction d'Évangéliaires manuscrits au sein

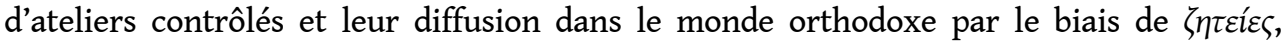
expliquent la persistance de la tradition byzantine. C'est ainsi seulement qu'ont pu être connus et transmis les anciens modèles iconographiques.

Des Grecs et des Arméniens travaillent à l'ornementation des vêtements brodés d'or des pachas et des beys, initiant les Turcs aux secrets du métier. Par ailleurs, la cour patriarcale et l'important clergé des Balkans et du Proche-Orient ont besoin d'habits sacerdotaux. L'attachement des orthodoxes à l'Église a comme conséquence l'épanouissement, pendant toute la période ottomane de l'art de la broderie en or. De nombreux Grecs viennent d'Asie Mineure à Istanbul, via Brousse, centre de la fabrication et du commerce de la soie. L'art de la broderie en or fleurit à Istanbul à partir du milieu $\mathrm{du} \mathrm{XVI}^{\mathrm{e}}$ siècle, et les commanditaires ne sont pas exclusivement les prêtres grecs, les pachas et les beys, mais aussi les boyards des principautés danubiennes et l'église russe. À la fin du XVII siècle, l'art de la broderie en or arrive à son apogée à Istanbul; pendant cette période les principaux éléments décoratifs ou iconographiques byzantins sont repris et fusionnent avec les influences occidentales. L'iconographie perpétue des sujets traditionnels, avec leur symbolisme fixé depuis des siècles; il s'y mêle pourtant des motifs végétaux issus de la décoration orientale. Parmi les brodeuses d'habits sacerdotaux les plus connues on peut nommer Despineta d'Argyris (1682-1723), Mariora (1723-1758), Efsevia (1723-1753).

\section{$\mathrm{XVIII}{ }^{\mathrm{e}}-\mathrm{XIX}{ }^{\mathrm{e}}$ siècles : naissance des éclectismes et nouvelles spécificités}

L'activité de construction déployée dans l'espace balkanique à partir du XVIII ${ }^{\mathrm{e}}$ siècle coïncide avec un épanouissement économique et culturel, conséquence d'événements de portée internationale, comme les traités de Karlowitz (1699), Passarowitz (1718) et Küçük Kaynarcı (1774), qui ont contribué à l'amélioration des conditions de vie des sujets chrétiens de l'Empire ottoman. Des clauses favorables au commerce et aux échanges ont encouragé le développement économique des peuples de la péninsule balkanique, phénomène qui se reflète dans la construction des églises paroissiales, et des domiciles réputés des archontes du centre de la péninsule. Le rôle de l'Église dans la construction des édifices religieux diminue progressivement. La charge de l'édification, la restauration 
ou la décoration des églises passe aux mains des donateurs, des communautés qui ont su acquérir une grande puissance dans la société balkanique traditionnelle. À partir du XIX siècle, ce sont les commissions ecclésiastiques qui se chargent de la supervision et du financement des travaux. Les vecteurs de la nouvelle architecture sont les fameux esnaf des maîtres ouvriers, dont les déplacements en groupe sont à juste titre mis en rapport avec la grande diffusion d'éléments formels et constructifs communs.

Dans l'architecture des églises des Balkans du Centre et du Nord, pendant la période 1700-1850, on distingue deux tendances différentes: d'une part, l'attachement aux valeurs traditionnelles qui favorise jusqu'à la fin l'expansion des procédés et des formes byzantins, d'autre part, la construction de grandes églises appartenant à des communautés, qui se fait à l'initiative et avec le financement des gens aisés. Les nouvelles églises, de grandes dimensions, érigées dans les centres des villes-métropoles, sont souvent, pour des raisons de sécurité, considérées comme des dépendances des monastères appartenant au Mont-Athos. Dans plusieurs cas, elles témoignent de la présence importante de la communauté chrétienne arménienne.

31 Les nouvelles tendances sont liées à un phénomène très intéressant : la diffusion massive de la basilique à trois nefs, avec un comble commun en bois ${ }^{16}$. Il s'agit de constructions de dimensions considérables, marquées par l'utilisation du bois tant dans la construction que dans l'aménagement intérieur. Le gynécée se développe à l'étage, dans la partie occidentale. La galerie qui d'habitude entoure les côtés méridional et occidental de l'église constitue un nouvel élément qui ajoute à l'échelonnement harmonieux des volumes tout en permettant la communication entre l'espace clos et l'espace ouvert.

Durant cette période encore, les plus grands et les plus importants monuments fidèles à la tradition post-byzantine $\mathrm{du}$ type athonite furent précisément les monastères conservateurs du Mont-Athos, où on assiste à la construction de six églises dans la période 1740-1830. Toutefois, le type athonite fut également suivi en Grèce centrale (Thessalie) et septentrionale (monastères de Klinovou, Néraïdohoriou, Drakotrypas, Zarkou, de Zoupani à Kozani et de Périvoli à Grévéna), mais aussi en Bulgarie (monastères de Trojan, Rila, de Lopuansky à Mihajlovgrad) et en Macédoine (monastère de Joachim Osogovsky à Krivorena Palanka).

Le trait commun de la construction des églises des XVIII ${ }^{e}$ et $\mathrm{XIX}^{\mathrm{e}}$ siècles réside dans l'adoption des formes propres aux styles européens du baroque et du rococo. Il est moins question d'une imitation de formes et de procédés de composition, que de la popularisation d'un répertoire décoratif qui a connu un grand succès dans l'Empire ottoman. L'absence de symboles religieux, la facilité de composition de motifs végétaux, géométriques et conventionnels, en favorise d'ailleurs la réception par tous les peuples de l'Empire, Turcs, Grecs, Slaves, Arméniens, Juifs. Les formes et les procédés stylistiques du baroque, venant d'Istanbul ou des pays catholiques d'Europe centrale, contribuent à ranimer l'art de la sculpture sur marbre et sur pierre, et à vivifier les façades des églises. Les clochers viennent achever la composition architecturale: il s'agit parfois de tours carrées (comme dans le Magne et dans les Iles ioniennes) ou de murs percés par des ouvertures symétriques cintrées comme dans les Cyclades.

À l'intérieur, les églises sont dotées d'une riche ornementation. Un des traits principaux de cette période est le recul progressif de la peinture murale au profit des éléments d'architecture et de sculpture qui commencent à dominer dans la composition des parties intérieures de l'église. Les morceaux d'architecture, soigneusement élaborés et peints, se 
substituent au simple décor peint de la période précédente: chapiteaux en bois en transposition baroque des styles classiques, décor polychrome en plâtre ou en stuc, arcades, plafonds en bois à fausses coupoles, paravents pour les gynécées, alignement soigné des dalles du sol, au milieu duquel figure l'aigle bicéphale. Dans les iconostases s'expriment des thèmes illustrant la pensée religieuse officielle, cohabitant de façon singulière avec des motifs païens et des sujets empruntés à la civilisation populaire ${ }^{17}$. L'art de la sculpture sur bois atteint son apogée, en se combinant ingénieusement avec la peinture. Dans les compositions peintes prédominent des panoramas de villes réelles ou imaginaires, des paysages (lacs et rivières), des fleurs et des fruits. Ces représentations s'inscrivent dans le cadre de la popularisation du baroque d'Europe centrale (le plus souvent connu à partir de gravures sur cuivre). Un répertoire iconographique commun, présent dans les maisons des archontes, les monastères et leurs dépendances, mais aussi dans les édifices publics turcs et les mosquées, révèle une fusion entre l'art religieux et l'art urbain ${ }^{18}$. Tant au niveau des formes que des modes de construction, il est évident que, vers la fin de cette période, toutes les valeurs architecturales de Byzance sont épuisées ou plutôt remplacées par une nouvelle tradition populaire largement marquée par des caractéristiques communes aux Balkans du Centre et du Sud.

Cette " Renaissance balkanique $~^{19}$ se traduit entre autres par une demande croissante de peintres $^{20}$. Le début du XVIII ${ }^{e}$ siècle témoigne de deux tendances différentes de la peinture des Balkans du Centre et du Sud. On pourrait parler d'un dédoublement culturel pendant la période ottomane, notamment dans la partie hellénophone de la péninsule. C'est en tout cas une oscillation entre la tradition byzantine et les nouveaux courants révolutionnaires de la Renaissance italienne, du baroque et des Lumières ${ }^{21}$. Ces mêmes styles contradictoires peuvent être relevés dans la peinture des églises de la Bulgarie, marquée, d'une part, par l'influence continue des tendances conservatrices du MontAthos mais perméable, de l'autre, aux nouvelles tendances transmises par les principautés roumaines. Dans les Balkans du Nord, tout au long du XVIII ${ }^{e}$ siècle, se produit un amalgame résultant de la fusion des éléments byzantins traditionnels avec des éléments architecturaux baroques. L'influence des centres catholiques d'Europe occidentale se fait sentir mais aussi celle de la Russie et de l'Ukraine orthodoxes, où les réformes de Pierre le Grand au début du XVIII ${ }^{\mathrm{e}}$ siècle, ont incité à une modernisation et à des remaniements jusque dans les églises bâties pendant la période médiévale tardive.

Plusieurs sujets de la Sublime Porte s'étaient installés en Europe centrale, en particulier à Vienne, centre important d'échanges commerciaux avec la Turquie. Des Serbes, des Grecs, des Bulgares, des Valaques, des Arvanites ont formé, au milieu du XVIII e siècle, de grandes communautés qui ont contribué à la renaissance culturelle des peuples dominés. Dans ces conditions, des artisans s'installent et travaillent dans diverses villes de l'Empire austro-hongrois, en combinant les thèmes de la tradition conservatrice byzantine et du dogme orthodoxe avec les formes novatrices du baroque d'Europe centrale.

En Hongrie, un important groupe d'églises est décoré de hautes iconostases dont les compositions sont fortement inspirées du style occidental. Les influences viennent de différentes sources : un groupe de peintres représente le style de l'école de Kiev, un autre groupe est formé par les peintres de Moschopolis (Voskopojë, en Albanie du Sud), qui vont introduire une Déisis de type particulier ; un troisième groupe est constitué par les représentants du "baroque serbe ", peintres qui avaient étudié à l'Académie de Vienne ou étaient influencés par elle. À partir du milieu du XVIII siècle, les grandes iconostases, influencées par l'école ukrainienne, couvrent entièrement l'entrée du sanctuaire, avec 
cinq séries d'icônes et une décoration baroque assez lourde. Elles seront le modèle de toutes les iconostases construites en Hongrie, indépendamment de la nationalité des commanditaires, serbes, roumains, grecs, valaques, hongrois ou autrichiens, et vont exercer une influence directe sur les églises construites pendant cette période dans les Balkans et au Mont-Athos. Parallèlement, est fondé à Vienne un atelier de broderie en fils d'or, dans lequel travaillent également des brodeurs et des brodeuses balkaniques. Le plus connu de tous, une véritable figure "interbalkanique » caractéristique de son époque, le diacre Christoforos Zefar (ou Zefarović ou Zefarovikis), originaire de Doïrane en Macédoine occidentale, a vécu au Mont-Athos où il a appris son art. Il a travaillé non seulement la broderie, mais aussi la peinture murale et surtout la gravure. Ses œuvres, broderies en or et autres, sont conservées en Grèce, en Serbie et en Roumanie.

L'introduction de styles étrangers et leur utilisation dans l'architecture d'édifices publics traduisait depuis le milieu du XVIII ${ }^{e}$ siècle une nécessité politique pour le pouvoir ottoman. Par la suite, des architectes étrangers, mais aussi des sujets ottomans ayant étudié dans les capitales européennes, introduisent de nouveaux types de bâtiments et de nouveaux styles architecturaux.

Dans les Balkans, l'éclectisme européen marque une rupture avec la tradition postbyzantine, alors que les formes qu'il propose conviennent à des types de bâtiments qui font pour la première fois leur apparition dans les grandes villes à la suite des réformes administratives et de la modernisation. Quant aux églises orthodoxes construites pendant la deuxième moitié du XIX ${ }^{e}$ siècle, profitant de l'abolition des restrictions de la période précédant le Tanzimat, elles s'élèvent dans des endroits bien en vue, tant dans le centre que dans les nouveaux quartiers de la ville. À la fin du XIXe siècle, elles s'écartent du type classique de la basilique pour suivre les modèles de l'architecture appelée "savante ». Mentionnons, à titre indicatif, l'église métropolitaine de Grigorios Palamas (1891-1914) à Salonique, de Saint- Georges à Korçë, de la Trinité à Gevgeli (1906) et de Saint-Paul à Kavala (1905).

Pendant la dernière phase de la période ottomane, au cœur des Balkans, les architectes continuent à se partager entre la tradition postbyzantine locale, étroitement liée aux restrictions sur la construction en vigueur avant le Tanzimat et l'architecture académique venu d'Europe. La pratique de l'éclectisme consiste à plaquer des façades néo-classiques sur les types connus et éprouvés de la construction byzantine ou encore à renforcer la valeur symbolique du produit final en y ajoutant des détails inspirés de l'architecture néo-romaine et néo-byzantine était très répandue, notamment en France, pendant cette période. L'église métropolitaine de Salonique, construite par E. Tsiller, dont l'œuvre a profondément marqué l'architecture néo-hellénique du dernier quart du XIX ${ }^{\mathrm{e}}$ siècle, est très typique de ce processus. Le passage à l'architecture éclectique et au caractère monumental ne peut se comprendre sans les revendications nationales qui se développent pendant cette période chez tous les peuples de la péninsule balkanique.

\section{Conclusion : continuités et ruptures}

41 Il est incontestable que les peuples balkaniques sous domination ottomane sont restés, en général, très conservateurs, alors que ceux qui ont vécu dans les régions sous domination ou influence occidentale, ont été plus ouverts aux nouveaux modes de pensée et d'action. 

marqué une étape décisive vers l'abandon de son caractère médiéval et l'adoption de nouveaux éléments qui ont contribué, particulièrement dans le cadre urbain, à réconcilier le monde médiéval avec l'époque moderne.

\section{Le Mont-Athos}

Le Mont-Athos, occupé une première fois par les Turcs de 1387 (1393) à 1403, fut définitivement conquis en 1428. En 1457 déjà, Mehmed le Conquérant avait reconnu par un firman tous les privilèges de la cité monastique byzantine.

Dans ce lieu qui, pendant des siècles, avait joué le rôle d'arche d'alliance de l'orthodoxie, la période post-byzantine est marquée par la construction d'un nombre considérable de monastères. Sept des plus grandes églises ont été construites entre 1514 et 1568 ; elles sont encore de nos jours en très bon état : ce sont celles des monastères d'Iviron (1514), Dionysiou (1539), Koutloumousiou (1540), Philothéou (1540), Stavronikita (1542), Xénophontos (1544) et Docheiariou (1568). Comme je l'ai déjà souligné, le type architectural dominant est le style appelé athonikos ou hagioritikos, conservant le plan de l'église en croix inscrite, qui apparaît au Mont-Athos à partir du $\mathrm{X}^{\mathrm{e}}$ siècle. Le type athonite est marqué par de grandes conques latérales destinées au «chœur» des 
chantres, au nord et au sud de la croix, par des arcades extérieures et un large narthex à piliers. La maçonnerie, les arcades aveugles autour desquelles s'articulent les façades, la coupole sur tambour polygonal et le reste des éléments architecturaux suivent la tradition des Paléologues bien établie en Grèce du Nord. Grâce au prestige et à l'autorité de leur origine, ces éléments sont des constantes de l'architecture monastique balkanique jusqu'à la période ottomane tardive. Dans ces ensembles monastiques a été également conservé un nombre considérable de bâtiments datant du XVI ${ }^{\mathrm{e}}$ au XIX ${ }^{\mathrm{e}}$ siècle, d'une valeur artistique et esthétique exceptionnelle: enceintes de fortifications, tours de défense, réfectoires, cellules, chapelles, clochers, fontaines, citernes, cuisines, hospices, hôpitaux, arsenaux. Les ailes des cellules avec leurs étages superposés, les balcons en bois, les hayat ${ }^{22}$ et les sahne ${ }^{23}$, constituent un complément fonctionnel indispensable du monastère, tout comme la cour extérieure: ces éléments donnent une couleur particulière, un dynamisme et une grandeur à l'espace, en associant les modes de construction et les formes de l'architecture laïque.

Les fresques et les icônes portatives, dont la liaison avec le culte est, naturellement, plus prononcée ici qu'ailleurs, constituent un souci permanent pour les moines, du double point de vue de l'orthodoxie dogmatique et de la qualité artistique. C'est la raison pour laquelle on a toujours tenu à faire venir de l'extérieur les meilleurs peintres de l'époque. Parmi les peintres crétois, l'on peut mentionner le moine Théophanès Strélitzas Bathas, qui réalise des fresques excellentes dans l'église principale et le réfectoire des monastères de Lavra (1535) et de Stavronikita (1546). Il peint aussi l'ensemble des icônes de l'iconostase et un grand nombre d'icônes portatives dans le monastère du Pantocrator, et celui de la Déisis au Prôtaton ${ }^{24}$ (1542). C'est à son école qu'appartient aussi la magnifique peinture murale des églises principales des monastères de Saint-Nicolas Anapafsa (1527) et de la Transfiguration (1552) aux Météores, Dousikou (1557), Roussanou (1560) et de l'église métropolitaine de Kalabaka (1560), en Thessalie. Les qualités principales de l'art de Théophanès sont une excellente facture, une grande richesse du répertoire iconographique -avec un florilège des modèles du style Paléologue du XIV siècle et des influences de Raphaël et de Bellini, telles qu'elles ont été transmises dans les Balkans grâce aux gravures sur cuivre de Marcantonio Raimondi- sans oublier une perfection dogmatique, alliée à des éléments qui conviennent à l'esthétique du public monastique auquel ils s'adressent, tout en répondant aux attentes des donateurs. Le rayonnement de son art a dépassé les frontières du Mont-Athos pour devenir en quelque sorte le modèle officiel de l'art de l'orthodoxie dans les Balkans, sa réputation se maintenant jusqu'à la fin du XVIII ${ }^{\mathrm{e}}$ siècle $^{25}$.

C'est encore à partir de la Crète qu'a été introduit au Mont-Athos l'art de l'iconostase en bois sculpté (grande iconostase du Prôtaton, 1611), avec des thèmes originaux de la Renaissance occidentale qui, fusionnés avec des éléments orientaux, seront discrètement intégrés dans les formes byzantines traditionnelles, tout en en respectant le style et la profondeur du contenu spirituel. Cependant, le monde balkanique de l'intérieur demeurant longtemps marqué par l'héritage de l'école de la Morava (liée à l'ancienne technique du bas-relief) la tradition du Mont-Athos va constituer le grand chantier où de talentueux sculpteurs sur bois venus de villages connus pour leur tradition artisanale, d'Épire (Metsovo, Konitsa, Grammos, villages de Korçë), de Macédoine occidentale (région de Kastoria), les Mijački de la région de Debar, créeront leurs nouveaux modèles; ces modèles, à partir du milieu du XVIII ${ }^{e}$ siècle, seront enrichis d'emprunts baroques et rococo parvenant du littoral adriatique, mais aussi d'Orient. Leurs œuvres, iconostases, 
sièges " despotiques ", ambons, pupitres, fruits d'une activité intense qui se prolonge tout au long du XIX ${ }^{e}$ siècle, dans la partie centrale de la péninsule balkanique, exercent une influence directe sur la formation du style local, par exemple à Samokov et à Trjavna en Bulgarie. Leur activité se déploie non seulement dans les églises chrétiennes, mais aussi dans les mosquées et les maisons richement décorées des archontes.

C'est un fait d'une grande importance que les monastères du Mont-Athos, tout en respectant rigoureusement les principes fondamentaux de la tradition conservatrice de l'orthodoxie orientale et tout en demeurant sous l'influence culturelle de l'élément dominant grec, vont de façon diachronique jouer un rôle de conservation et de rayonnement des caractéristiques nationales dans la conscience patrimoniale des peuples slaves de la péninsule balkanique : c'est le cas de Chilandari, pour les Serbes, de Zografou, pour les Bulgares, alors que la présence des Russes sera concentrée dans le monastère de Pantéléimon. Au milieu du XVII siècle, le moine Poimin, né à Sofia, après avoir fait son apprentissage dans le monastère de Zografou, rentre dans son pays pour restaurer plusieurs anciens monastères (Čerepisky, Seslavsky, Elešnišky, Suhodolsky). Le moine Païsios rédige la première Histoire slavo-bulgare (1762) en se servant de livres anciens et de manuscrits du même monastère. Zaharii Hristov (Zograf), le plus grand peintre bulgare de cette période, qui réalise la peinture de la nef médiane de l'église principale du monastère de Rila, va, en 1852, faire les fresques du narthex du monastère de Lavra, pendant du modèle athonite. Au début $d u X_{V I I}{ }^{e}$ siècle, le moine Serbe Georgije Mitrofanović apprend son art au Mont-Athos et fonde un grand atelier à Chilandari (iconostases des chapelles annexes des monastères de la Synaxis ton Archangelon et de Saint-Tryphon, fresques du réfectoire), alors qu'il va créer une série d'icônes, iconostases et fresques (1615-1622) en Dalmatie (monastère de Krupa), en Herzégovine et au Monténégro (monastères de Morača, Dobričevo, Zavala, Žitomislić, Pljevlja), et enfin en Serbie du Sud (ermitage de Saint-Savas, à Studenica, église Saint-Démétrius et réfectoire du Patriarcat de Peć) $)^{26}$.

52 La conquête ottomane fut loin de diminuer la production de copies de manuscrits dans les monastères du Mont-Athos. Tout au contraire, la volonté de satisfaire la demande croissante d'églises et de monastères a encouragé l'intensification, dans le cadre d'ateliers organisés, de la production de copies manuscrites de textes liturgiques byzantins dans toutes les langues slaves des Balkans ${ }^{27}$.

$53 \mathrm{Au} \mathrm{XVIII}{ }^{e}$ siècle, au moment de la prédominance, dans l'architecture religieuse des Balkans, d'une tradition populaire résultant de l'intégration d'éléments du style « turcobaroque ", les plus grands et les plus importants monuments fidèles à la tradition postbyzantine furent encore les monastères conservateurs du Mont-Athos. Soixante-dix ans durant après 1746 , on y construit et y décore sept grandes églises, toutes dans le style traditionnel athonite : Philothéou (1746), Xiropotamou (1761), Grigoriou (1770), Zografou (1800), Esphigménou (1806), Saint-Pantéléimon (1812) et Saint-Paul (1817). Ce nouvel épanouissement du Mont-Athos est lié à l'essor économique des Grecs d'Istanbul et à celui des autres peuples balkaniques dans les principautés danubiennes, en Europe centrale et en Russie. Les grands commerçants qui avaient fait fortune, les Phanariotes, qui détenaient des postes importants en se mettant au service du conquérant, les tsars orthodoxes russes et surtout les princes danubiens deviennent les nouveaux bienfaiteurs des monastères. Ils acquittent les lourds impôts, font restaurer et embellir les bâtiments, font exécuter des icônes, des vases sacrées, des tombeaux, des livres et des manuscrits ; leurs dons concernent même des dépendances lointaines $(\mu \varepsilon \tau o ́ x ı \alpha)^{28}$. Pendant les voyages 


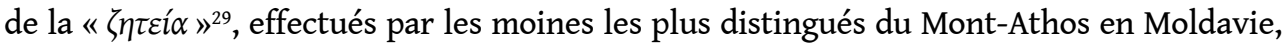
à Kiev ou à Moscou, ceux-ci donnent en remerciement des évangiles manuscrits et des livres liturgiques, ainsi que des chroniques de princes et d'archevêques médiévaux. Plusieurs de ces moines restent des années dans les principautés danubiennes ou en Russie, organisant la vie spirituelle dans ces pays. Ce phénomène est significatif du prestige durable dont le Mont-Athos a joui parmi les peuples orthodoxes de la péninsule balkanique et même au-delà.

Durant cette période, se forme au Mont-Athos un style de peinture comportant des traits locaux. Il est significatif que le prêtre et peintre Dionysios de Fourna à Agrafa (Grèce occidentale), auteur d'une Interprétation de l'art de la peinture (vers 1730), apprenne sur place l'art de la peinture. Dans ses textes il incite ses élèves à imiter les œuvres de Théophanès et du peintre byzantin réputé Protatos Manouil Pansélinos de Salonique. Le manuel enseigne tout sur la préparation des couleurs et les bases des icônes, décrit en détail la représentation de chaque saint et présente de façon détaillée le répertoire iconographique adapté au type d'église. L'Interprétation sera traduite dans presque toutes les langues balkaniques, constituant le principal manuel de référence pour tous les ateliers de peintres ambulants dans la réalisation de répertoires iconographiques des églises. Il est évident que l'Interprétation de Dionysios vise à préserver la tradition de la peinture byzantine qu'il traite d'ailleurs d'« art sacré ». Cette tendance rétrospective de retour au style Paléologue est également représentée par d'autres peintres, comme David Sélénitziotis d'Avlona en Albanie, qui réalise la fresque du grand narthex de la chapelle de la Portaïtissa à Lavra (1715), et travaille aussi à Moschopolis et à Kastoria; toutefois dans ses productions, toutes marquées de finesse et d'originalité, on ressent le contact avec les œuvres occidentales.

Dans la deuxième moitié du XVIII ${ }^{\mathrm{e}}$ siècle, la présence du baroque levantin dans la décoration intérieure et extérieure des églises, mais aussi dans le répertoire iconographique, devient plus pesante. À la fin du XIXe siècle, dans les ateliers du MontAthos prédomine le langage pictural occidental, notamment celui du style " Nazaréen», basé sur la technique de la peinture à l'huile qui influence d'autres peintres balkaniques.

\section{Le monastère de la Mère de Dieu à Bačkovo en Bulgarie}

Le monastère de la Mère de Dieu, dit Pétritsonissa, à Bačkovo est le plus ancien et le plus important de Thrace du Nord. Il se dresse au sud-est de la citadelle de Sténimachos (Assenovgrad), dans un site merveilleux, sur la rive droite de la rivière Čepelare. Sa fondation, en 1083, est due au général byzantin d'origine géorgienne Grigorios Pakourianos. Le monastère de Bačkovo fut d'emblée l'un des plus importants centres religieux et spirituels byzantins dans les Balkans. Sa conservation s'appuie sur une base culturelle enrichie par la présence et l'interaction de différents peuples. Jean Pétrosis, un des plus importants érudits géorgiens, $\mathrm{y}$ a vécu pendant trente ans, avant de s'installer au monastère de Gelati, en Géorgie (début XVII ${ }^{e}$ siècle). C'est encore ici, bien auparavant, que s'était retiré jusqu'à sa mort saint Efthymios, archevêque de Tirnovo, après la conquête de la ville par les Turcs (1393). De son côté, le "philosophe » et "maître des Serbes", Constantin Kostenečki avait été formé ici, avant de se réfugier, en 1410, au despotat serbe de Stefan Lazarević.

Le monastère possédait une bibliothèque riche en manuscrits et chrysobulles, ainsi qu'un scriptorium où l'on reproduisait les ouvrages théologiques et les œuvres de grands 
écrivains grecs de l'Antiquité. La très originale charte du monastère, conservées par trois copies (en grec, en géorgien et en arménien) nous apprend beaucoup sur l'organisation des communautés monastiques et les structures sociales dans la Thrace du XIe siècle. Le monastère primitif a été détruit à la fin $\mathrm{du} \mathrm{XV}^{\mathrm{e}}$ et au début du XVI $\mathrm{X}^{\mathrm{e}}$ siècle. En 1588 , les travaux de reconstruction furent entrepris à l'initiative et sous le contrôle des métropolites de la ville voisine de Philippoupolis, le financement étant assuré par les maîtres des principautés danubiennes. Ces travaux ont duré pendant cinquante ans.

Sous sa forme actuelle, le monastère comporte deux parties principales: la cour septentrionale, construite en 1083 et la cour méridionale, aménagée au XIX ${ }^{\mathrm{e}}$ siècle, puis détruite par un incendie et restaurée de nouveau. Les recherches confirment la conservation de la forme initiale, fermée, de la cour septentrionale primitive au cours des aménagements et des remaniements du XVII ${ }^{e}$ siècle. Le caractère de fortification inaccessible de la construction a perpétué dans le temps la tradition médiévale ; les murs extérieurs sont renforcés par un système de contreforts, alors que la porte principale, située du côté oriental, maintient jusqu'à aujourd'hui son caractère défensif. Les ailes contenant les cellules se développent autour de la cour centrale ; elles ont deux étages et sont adaptées au relief. Au rez-de-chaussée se trouvaient les écuries et les réserves et, dans la partie méridionale, le réfectoire, la cuisine et la cave ; à l'étage, le prieuré, les cellules des moines et l'hôtellerie. Au milieu du XIX ${ }^{e}$ siècle, dans la partie méridionale de l'ensemble monastique médiéval furent rajoutées trois ailes, en forme de $\mathrm{P}$ tout autour de la cour fermée ; au milieu de la cour, fut érigée l'église de Saint-Nicolas.

L'actuelle église post-byzantine du monastère, l'église de la Panagia, est une lourde construction en pierre de taille, réalisée en 1604 selon le modèle athonite. La structure et les techniques de construction de l'église montrent l'intervention d'un groupe spécialisé venu d'Épire. Ces praticiens maitrisaient parfaitement la typologie des églises athonites, déjà exprimée dans le monastère de la Transfiguration (Grand Météore, construit en 1544, fresques de 1552) et de façon pratiquement identique dans l'église du monastère de Pétra dans le Pinde méridional (construite aux environs de 1550).

En 1642, l'iconostase actuelle, la plus importante des iconostases anciennes conservées en Bulgarie, a été installée. C'est sans doute l'œuvre de sculpteurs sur bois venus d'Épire. Le répertoire formel des bas-reliefs comporte une riche décoration végétale, avec des éléments du répertoire occidental (épines et feuillages entrelacés, frontons de forme gothique, lions et dragons ailés), réalisée avec virtuosité et dans un fourmillement de détails remarquables selon la tendance développée dans la sculpture sur bois crétoise au $\mathrm{XVI}^{\mathrm{e}}$ siècle, transmise au XVII ${ }^{\mathrm{e}}$ siècle dans les Iles ioniennes (en particulier à Zakynthos), puis par la suite dans les ateliers épirotes ${ }^{30}$. La peinture du narthex de l'église a été réalisée en 1643 grâce à l'appui financier généreux de « l'archonte Georges » et de son fils Constantin, hauts représentants de l'État en Moldavie ${ }^{31}$, et sous la supervision de l'archevêque de Philippoupolis, Christophoros. Leurs portraits en pied ornent la façade occidentale de l'édifice, à côté de ceux des saints. Les mêmes donateurs ont aussi financé la peinture du réfectoire du monastère, construit en 1632, l'un des plus importants de la période ottomane. Il s'agit d'une salle rectangulaire, surmontée d'une voûte en berceau, terminée par deux absides sur les petits côtés. La table est en marbre et se prolonge du côté occidental où se trouve la place de l'higoumène. Les parois sont ornées de fresques de grande qualité artistique qui parviennent à créer une ambiance d'une extrême spiritualité. La surface de la voûte est entièrement recouverte de représentations des ancêtres de Jésus (Arbre de Jessé) où apparaissent également des philosophes grecs de 
l'Antiquité32. La voûte est encore illustrée de cycles de l'hymne Acathiste pour la Mère de Dieu, de conciles, de la Déisis et la Seconde Parousie du Messie.

61 En 1841, le Bulgare Zaharii Hristov (Zograf) originaire de Samokov réalise, dans un style très expressif, la peinture murale de l'église, plus récente, de Saint-Nicolas, située dans la deuxième cour du monastère. Dans le narthex où est représenté la Seconde Parousie du Messie, on voit parmi les pécheurs conduits vers l'enfer les riches $\tau \sigma o p \mu \pi \alpha \tau \zeta \zeta \eta_{\delta} \delta \varepsilon \zeta^{33} \mathrm{de}$ Philippoupolis, accompagnés de leurs épouses, portant les costumes typiques de la région. En 1846, Alexios Athanasiou, originaire de Naoussa en Macédoine occidentale, peint le "panorama", une grande fresque sur la paroi de l'aile méridionale, avec la représentation historique du monastère et de sa région. En 1850, enfin, Jean Moschos achève la peinture de l'intérieur de l'église, dans un style pictural plutôt populaire.

La collection ecclésiastique d'offrandes du monastère est une des plus riches de Bulgarie. Elle comporte: des images des $\mathrm{XV}^{\mathrm{e}}$-XIX ${ }^{\mathrm{e}}$ siècles, une icône de la Mère de Dieu (1310) portant une dédicace en géorgien sur un revêtement en argent, un épitaphios (XIV ${ }^{\mathrm{e}}-\mathrm{XV}^{\mathrm{e}}$ siècles), des habits sacerdotaux, des évangiles avec des couvertures en argent, des chandeliers, des plateaux, des calices, des reliquaires, des croix de table en bois et des ciboires, et le beau coffret rehaussé d'or et d'argent, incrustée avec une décoration perforée en émail, imitant celui de l'église de Saint-Marc de Venise, un des plus précieux de son genre dans les Balkans (1637).

63 Le monastère conserve également la trace des productions d'un important atelier de transcription et de traduction en bulgare de textes sacrés ainsi que de florilèges de textes religieux appelés « Damaskin $»^{34}$.

De la période initiale de la construction de l'église sont conservés aujourd'hui, presque intacts, à proximité du monastère, les caveaux funéraires. C'est un exemple unique dans l'architecture ecclésiastique médiévale des Balkans. Dans la composition et la forme architecturales de ce monument funéraire, on distingue bien l'interpénétration de la tradition byzantine et des influences caucasiennes, liées à l'origine géorgienne du fondateur du monastère. Il s'agit d'une construction à deux niveaux : les deux étages sont rectangulaires, avec de larges narthex et des absides polygonales à l'Est. Ils sont couverts de voûtes en berceau, alors que les surfaces extérieures des murs sont décorées d'arcs doubleaux aveugles, appuyés sur des demi-colonnes. L'étage supérieur était consacré aux cérémonies funéraires, alors que l'étage inférieur, destiné à la sépulture des moines, comportait quatorze tombes. La maçonnerie étant constituée d'assises superposées de tuf et de briques, les parois intérieures des deux étages sont recouvertes de fresques, réalisations importantes des ateliers liés à la cour impériale de Constantinople sous les Comnènes (milieu du XII ${ }^{\mathrm{e}}$ siècle).

\section{Le monastère de Saint-Jean Bigorsky en Macédoine et l'école de Debar}

65 Le monastère de Saint-Jean Bigorsky ${ }^{35}$ est l'un des plus importants monastères dépendant de l'archevêché historique d'ohrid. Il est situé sur la frontière de l'ex-république yougoslave de la Macédoine avec l'Albanie, au nord-est de Debar, dans la région de Mala Reka. Le site, remarquable par la nature d'une roche poreuse, se trouve dans la vallée pittoresque de la Radika, affluent du Drim. D'après les archives du monastère, il fut fondé en 1020 par un certain Jean ${ }^{36}$. Le monastère initial a été détruit, probablement à l'arrivée des Turcs; seule subsiste une petite chapelle. En 1743, le moine Hilarion a refondé le 
monastère, construisant de nouvelles cellules et achetant des champs et des vignes. L'église actuelle a été construite en 1800, à l'initiative de l'higoumène Mitrophane. Son élève et successeur, l'actif archimandrite Arsénios, a fait don au monastère de nouveaux champs et a fait construire, en 1814, la haute aile septentrionale du monastère et, en 1825, le grand réfectoire. Au rez-de-chaussée se situent les entrepôts et les ateliers de production. Dans les étages, desservis par de larges balcons en bois, se trouvent les cellules des moines et le prieuré contenant les archives. Les hôtelleries pour les pèlerins, ornées de plafonds en bois sculpté, portent les noms des villages d'origine des donateurs. Dans le côté occidental du réfectoire, conçu pour le service de deux cents moines, des parois entièrement peintes représentent des scènes bibliques et des portraits en pied des higoumènes. Le monastère était protégé par une petite tour où veillait un gardien armé. L'église principale, de grandes dimensions, comporte des murs épais, bâtis en blocs de tuf étroits et de hauteur égale. Il s'agit d'une église unique en raison de sa structure particulière : le plan de la nef centrale est carré, avec une abside semi-circulaire à l'Est et deux élargissements latéraux (comparables aux «chœurs " athonites); mais elle se raccorde directement au narthex, où quatre puissantes colonnes supportent une coupole aveugle de base polygonale. Le vaisseau central est, lui-aussi, surmonté d'une coupole aveugle analogue, mais plus grande, et avec une calotte à sphères multiples dont l'échelonnement, visible à l'extérieur de l'église, lui donne l'aspect d'une mosquée ottomane.

L'église est particulièrement réputée pour son iconostase en bois sculpté, chef-d'œuvre de l'école de maîtres « Mijacki » et certainement l'une des plus grandes réalisations visibles dans les Balkans. Elle est l'œuvre d'une équipe connue de maîtres "venant de Debar " (Debar> « debarlja »), dont le chef était Petar Filipović (Garkata) et les membres, son frère Marko et Makarije Negri Frćkovsky ${ }^{37}$ (1830-1840). L'iconostase se divise en six zones horizontales et se prolonge du côté de deux proskynitaria latéraux. La zone inférieure comporte des motifs végétaux et animaux, parmi lesquels apparaissent des figures humaines, parfois isolées, parfois intégrées à des compositions à plusieurs personnages, avec des représentations de scènes de l'Ancien et du Nouveau Testament. Au-dessus des icônes " despotiques ", on relève une série d'anges, un décor végétal de la vigne (symbole de l'Eglise) et d'épines. Les deux zones supérieures comportent des scènes tirées du calendrier des saints et des apôtres ${ }^{38}$. Le peintre Michel Anagnostis et son fils Dimitrios, originaires d'un village valaque de maîtres architectes, Samarina, dans la région de Grévéna, ont été invités au monastère et après trois ans de travail, ont achevé, en 1831, la peinture de l'iconostase ${ }^{39}$. En 1849, Dičo Zograf, peintre venu du village voisin de Tresonče a réalisé les fresques de la voûte aveugle du vaisseau central de l'église. Il y a représenté le Tout-Puissant, entouré d'un chœur d'anges et de saints, et de scènes du cycle de la vie du Christ; il a aussi peint dans le réfectoire des portraits d'higoumènes, influencés par l'art de ses prédécesseurs ${ }^{40}$.

67 Non loin du monastère se trouvent les villages où sont nés plusieurs peintres et sculpteurs sur bois des XVIII ${ }^{e}$ et XIX ${ }^{e}$ siècles, de l'« école de Debar » dont le rayonnement fut si grand qu'il ne saurait être comparé qu'à l'école crétoise. La région géographique s'appelle «mijacki » et comprend deux groupes de villages : vingt-quatre à Mala Reka et vingt-trois à Golema Reka. Les maîtres sont originaires des villages de montagne: Galičnik, Lazaropolje, Tresonče, Grai, Rosoki, Osoj, Malo et Golemo Selce. Selon l'usage, les groupes de maîtres se composaient exclusivement de membres de la même famille, et pouvaient comporter jusqu'à trois générations de maîtres. Les maîtres "Mijacki» se 
déplaçaient en automne et revenaient dans leur village en mai-juin. Ils voyageaient en groupes organisés (taifa) qui couvraient tous les domaines de la construction : tailleurs de pierre, maçons, charpentiers, sculpteurs, plâtriers ${ }^{41}$, peintres d'icônes portatives et de fresques. Dès leur plus jeune âge, ils suivaient un apprentissage généraliste pour se spécialiser, par la suite, dans un art. Cette organisation leur permettait non seulement de bâtir une église, mais aussi d'en construire les parties en bois, de réaliser les fresques et les icônes portatives, de sculpter l'iconostase en bois, l'ambon, le siège épiscopal et son baldaquin et enfin de réaliser les reliefs en plâtre et les décorations polychromes. Polyvalents, les « Mijacki » ont travaillé dans des églises chrétiennes, mais aussi dans des mosquées et des maisons d'archontes ou de riches aghas.

Les plus importantes iconostases exécutées par les "Mijacki» se trouvent ou se trouvaient dans les églises de l'Archange Michel à Lesnovo (1814), du Christ Sauveur à Skopje (1824), de Saint-Nicolas et de la Mère de Dieu à Prilep, de Saint-Georges à Prizren (1829, brûlée en 2004), de la Mère de Dieu à Skopje (1840, brûlée pendant la deuxième guerre mondiale), de Saint-Nicolas à Priština (1843, brûlée en 2004), de Saint-Nicolas à Krušovo (brûlée en 1903 pendant l'insurrection d'llinden), de la Mère de Dieu «Kamenska » à Ohrid. Des maîtres venus d'Opar ont sculpté les iconostases des églises épiscopales de Berat (1806) et d'Elbasan (1859), ainsi que celles de Sainte-Paraskévi à Përmet, en Albanie. Un grand nombre d'iconostases a été exécuté en Bulgarie : les plus importantes se trouvent à l'église de la Mère de Dieu à Pazardik (1845) et au monastère de Rila (1843) ${ }^{42}$. Leur travail en Grèce du Nord n'a pas encore été étudié, mais il est bien connu qu'ils ont travaillé à Salonique, Édessa, Serrès, Drama. Pourtant, les chercheurs sont d'accord pour admettre que leur art s'est développé le long des routes de pèlerinage conduisant au Mont-Athos ${ }^{43}$.

Les caractères propres de l'école de Debar ne résident pas seulement dans la quantité ou la qualité de sa production, mais aussi dans les innovations que les maitres ont adoptées et intégrées dans leurs œuvres, et qu'ils ont défendues dans l'ambiance culturelle de l'époque. À une période où l'art du portrait n'était qu'à ses débuts, ils ont prévu les possibilités du genre et l'ont adopté mais, à cause des contraintes de l'époque, dans le seul cadre de la sculpture sur bois des églises. Dans leur art ils ont défendu un nouveau principe, celui de la représentation des personnages, dans le cadre d'une décoration baroque. C'est la seule école de sculpture sur bois qui soit parvenue chez les slaves du Sud à exprimer cette représentation à travers un grand nombre de compositions de contenu très diversifié qui ne s'arrêtent pas aux scènes bibliques, mais s'étendent également à une multitude de scènes du quotidien. Ils sont, de cette façon, arrivés à transcender le rôle traditionnel de l'iconostase, qui était considérée exclusivement, dans la tradition médiévale, comme cadre décoratif pour les icônes.

\section{Moschopolis et le rayonnement de son art dans les Balkans et en Autriche-Hongrie}

70 Moschopolis -aujourd'hui Voskopojë- fut le centre culturel le plus important d'Albanie du Sud aux XVII et ${ }^{e}$ XVIII ${ }^{e}$ siècles. La prospérité de la ville est attestée par les fameux pèlerinages au monastère de Saint-Naoum sur le lac d'Ohrid et au monastère de SaintJean-Prodrome à Shipska, par son imprimerie unique d'où sont sorties vingt éditions, par la renommée de ses peintres (locaux ou étrangers de passage, travaillant dans les églises de la région), par ses ateliers de manufacture, par la richesse de ses commerçants. Le 
commerce de l'Adriatique avec l'exportation de produits de Durrazo à Venise, à Ancône et à Raguse et les traités de paix et de commerce de Karlović (1699), de Pasarević (1718), de Belgrade (1739), ont entraîné les commerçants de Moschopolis sur les marchés des principautés danubiennes, de Vienne, de Hongrie, de Pologne, de Russie et d'Allemagne. Dans la " Nouvelle Académie », l'une des plus importantes institutions d'enseignement des Balkans, Jean Halkias, originaire de Moschopolis, directeur de l'École de Flanghinis à Venise, est professeur.

71 Parmi la vingtaine d'églises que comptait la ville, il n'en subsiste que cinq, ainsi qu'un monastère. Ces témoins sont pourtant les plus importants monuments de cette période. Le monastère de Saint-Jean-Prodrome se situe au nord de la ville; sa fondation remonte à 1632, sa décoration date de 1659. Son église principale (le plus ancien monument conservé de Moschopolis) comporte la nef et un narthex construit postérieurement dans le style athonite. Il a fallu soixante-dix ans pour que la construction d'édifices religieux reprenne son élan. Elle fut finalement si intense que pendant la période 1694-1724 furent élevées quatre grandes églises de type basilical.

72 L'église de l'Assomption de la Mère de Dieu est la plus grande et constitue la cathédrale de la ville. Elle a été construite pendant la période 1694-9, alors que sa peinture a été achevée en 1712 par Théodore, Anagnosti et Stériano venant d'Agrafa. L'église de SaintNicolas, l'une de plus belles églises de la ville, a été bâtie en 1722 et décorée en 1726 par un des peintres les plus connus de cette époque, David de Sélénitza. La fraîcheur de l'imagination qui s'exprime dans ses abondantes fresques suscite l'étonnement. Il a très méticuleusement représenté le milieu des citoyens de la ville où il a vécu. On lui doit également la beauté expressive du diacre Stéphane, le prôtomartyr, et le portrait en pied du riche dignitaire Hatzigiorgi, premier portrait réaliste, ainsi que la représentation du semeur, l'une des plus parfaites fresques du XVIII ${ }^{e}$ siècle ${ }^{44}$. Les fresques du porche ont été réalisées par les frères Constantin et Athanase de Korçë.

73 L'église des Archanges a été sans doute bâtie en 1696 et peinte en 1722. L'église de SaintAthanase, construite en 1724 par l'équipe de maîtres Andronis, Michel, Pavlos, Manthos, du village de Krimini, a été peinte en 1744 par les frères Constantin et Athanase de Korçë. L'église des Taxiarques fut probablement bâtie en 1696 et peinte en 1722. L'église de Saint-Athanase, construite en 1724 par l'équipe de maîtres Andronis, Michel, Paul et Mathieu, du village de Krimini ${ }^{45}$, a été peinte en 1744 par les frères Constantin et Athanase de Korçë.

74 Ces quatre églises sont des basiliques à trois nefs. Un large toit à deux pentes couvre l'édifice de façon uniforme et ce n'est qu'en pénétrant à l'intérieur qu'on réalise la majesté et la répartition de l'espace. Les églises comportent une nef centrale, un narthex du côté occidental et un porche du côté méridional. La maçonnerie est soignée, en pierre de taille et mortier. Sur les faces orientales on peut voir des arcs aveugles, alors que les parois des porches se signalent par une décoration abondante, combinant briques et tuf.

75 Les églises de Moschopolis appartiennent au type des basiliques à trois nefs les plus anciennes de l'architecture post-byzantine de la péninsule balkanique centrale. Leur trait caractéristique réside dans le fait qu'elles sont liées à la tradition byzantine par l'emploi de différents types de voûtes de pierres pour couvrir les parties secondaires de l'édifice. L'émigration des Arvanito-valaques de Moschopolis et du Pinde, aux XVIII ${ }^{\mathrm{e}} \mathrm{XIX}{ }^{\mathrm{e}}$ siècles, comme bergers, artisans qualifiés et commerçants dans diverses régions de la péninsule centrale, est à l'origine de l'édification dans ces provinces de grandes églises en pierre de 
taille, dont la technique compliquée rompait avec la tradition locale de la construction en bois ${ }^{46}$.

En effet, de nombreux artistes épirotes sont originaires de Moschopolis et des alentours. On trouve parmi eux le moine Constantin, qui a réalisé les icônes de l'iconostase des églises de la Mère de Dieu dans la ville même (1720) et d'Hosios-Naoum sur le lac d'Ohrid (1711), alors que les peintres Théodore et Stérianos originaires d'Agrafa du Pinde ont décoré, en 1717, l'église de la Mère de Dieu. Le peintre Théodore a également réalisé les fresques de la chapelle de Saint-Efthymios dans la ville et Dimitrios Phistovikios, originaire de Shipska, a travaillé à Skradin en Dalmatie. La famille des peintres Cetiri de Grabova, non loin de Moschopolis, s'est chargée de la décoration intérieure de certaines églises albanaises ${ }^{47}$. Par ailleurs, les gravures sur cuivre ont joué un rôle important pour la peinture du XVIIIe siècle. Les Vies de saints locaux, éditées dans l'imprimerie de la ville, ont contribué à la propagation de leur culte et à une plus large diffusion de celui-ci dans l'espace balkanique.

La destruction de Moschopolis, en 1769, a entrainé une vague d'émigration vers les Balkans du Nord et l'Europe centrale, où les riches Moschopolitains ont entretenu des liens avec les communautés grecques orthodoxes de l'Empire austro-hongrois et ont joué un rôle de premier plan dans le commerce avec l'Orient. Des églises communales de Hongrie ont été consacrées à Hosios-Naoum (Miscolc, Gyöngyös). Les peintres de fresques ou d'icônes dans des églises communales orthodoxes étaient le plus souvent originaires de Moschopolis. En Hongrie, la famille Cetiri a beaucoup travaillé (icônes à Miscolc, Székesfehérvar), ainsi que les frères Michel et Pierre Symeonović, auteurs des fresques des églises orthodoxes à Raćkeve (île Csepel) et de Székesfehérvar (Stuhlweissenburg). En 1765, le peintre Théodore Simos a réalisé les fresques de la chapelle des Saints Cosmas et Damianos de Raćkeve, au sud de Budapest et de l'église orthodoxe de Székesfehérvar (1774). Certaines icônes portatives peintes de sa main se trouvent actuellement dans les musées hongrois.

Les orfèvres moschopolitains étaient considérés comme des artistes de grande valeur par l'Église orthodoxe serbe ; ils ont largement contribué au développement de l'art décoratif serbe. En 1775, il y avait trente orfèvres dans la ville de Novi Sad, en majorité valaques. Parmi eux se trouvait Georges Argyris, l'un des artisans les plus productifs de la région de la métropole de Karlovci; il a notamment fait l'éventail liturgique du monastère de Krušedol (1724), des tissus rehaussés d'argent pour le livre des Évangiles, dans la cathédrale de Belgrade et dans les monastères de Šišatovać (1742) et de Banat à Vojilovica (1728), ainsi que des offrandes en argent à Saint-Nicolas de Novi Sad (1750) et au monastère de Gormirje (1748).

\section{Un Mont-Athos serbe : les monastères de Fruška Gora}

Dans la région montagneuse de Fruška Gora, située entre Save et Danube, l'existence de trente-cinq monastères est attestée durant la période ottomane, dans le seul chef-lieu de la ville de Srem (Sremska Mitrovića). Les origines de certains monastères remontent à la première moitié $\mathrm{du} \mathrm{XV}$ siècle. Ils jouaient le rôle de phares pour les colonies orthodoxes isolées dans la mer du catholicisme hongrois. À partir du début du XVe siècle, trois puissances -Hongrie, Turquie, Autriche- se voient contraintes, l'une après l'autre, de faire preuve de tolérance religieuse, afin de conserver les Serbes sur la ligne frontalière, le long du Danube. Pendant sa longue présence, la population serbe locale, constamment 
alimentée par les réfugiés venus du Sud, jouit d'une série de privilèges. Ces conditions vont lui permettre de rénover les anciens centres religieux et d'en créer de nouveaux. Après la grande immigration serbe de 1690 , la lutte pour la conservation et la restauration des monastères se poursuit. Il en va de même après le départ définitif des Ottomans de Srem (1717), pour le renouvellement des privilèges. De nos jours, après une série de catastrophes, de ravages et de rénovations, notamment après les dégâts provoqués par la deuxième guerre mondiale, seize monastères seulement sont conservés.

On a de nombreux documents sur la fondation des monastères de Fruška Gora. Aux modestes églises primitives en bois construites par les réfugiés se substituent de nouveaux édifices, appartenant à deux périodes marquées par deux traditions architecturales différentes: la période byzantine (fin $\mathrm{XV}^{\mathrm{e}}-\mathrm{XVI}^{\mathrm{e}}$ siècle) et la période baroque (XVIII ${ }^{e}$ siècle). Les églises érigées au XVI ${ }^{e}$ siècle appartiennent en général au type d'église à trois conques; c'est un des éléments qui révèlent les rapports avec l'école de la Morava dans l'architecture médiévale serbe. C'est l'église principale du monastère de Krušedol qui influença les premiers monastères de Jazak, Rakovac, Novo Hopovo, Petkovica, où sont conservées les fresques les plus anciennes (milieu du XVI ${ }^{\mathrm{e}}$ siècle). Le prestige dont jouit de façon durable le monastère serbe de Chilandari en fait le modèle du rayonnement de l'esprit unifié de l'orthodoxie athonite dans les régions danubiennes. Les moines invités sans distinction de Vatopédi ou de Lavra s'y sentent à l'aise parmi les Serbes, les Bulgares et les Valaques de la paroisse de Sremski Karlovći.

81 Un autre groupe d'églises, construites le long de la Drina après la reconstitution du Patriarcat de Peć (1557), appartient au type architectural de l'école de Raška : églises des monastères de Velika Remeta, Vrdnik-Ranavica, Grgeteg, Divša, Mala Remeta, Kuveždin. Dans l'église à nef unique, avec une grande abside semi-cylindrique, des extensions latérales rectangulaires sont construites sur le modèle des « chœurs » athonites.

82 À Krušedol, l'église est érigée à l'initiative de l'archevêque Maxime (connu sous le nom de despote Georgije Branković), elle est peinte, en 1522-3, par une équipe mixte de peintres grecs et serbes venus du Mont-Athos ou de Valachie. Le renouveau du culte de tsars et de despotes médiévaux -des Branković, de Stefan Dečanski, de Milutin-, des saints serbes Savas et Syméon, constituerait la preuve des origines séculaires de la nation et l'expression de son intégrité nationale, indispensables à sa survie. A Jazak, les marches en bois sculpté de l'iconostase initiale (environ 1522), en bas relief à décoration végétale, révèlent l'intervention des ateliers de Macédoine occidentale, alors qu'à Petkovica est conservée une croix du XVII siècle.

La fondation du monastère de Novo Hapovo remonte à la fin du $\mathrm{XV}^{\mathrm{e}}$ siècle (il est déjà mentionné dans le plus ancien recensement ottoman, datant de 1546). L'église principale actuelle fut érigée en 1576, grâce aux donateurs Lacko et Marko Jovšić, citoyens de Gornji Kovin. Le voyageur allemand Stefan Gerlach (1573-8) la qualifie d'« école monacale ». L'église principale appartient au type athonite, avec un grand narthex à l'Ouest et deux absidioles à l'Est au niveau de la prothèse et du diaconicon. La maçonnerie est constituée de pierres argileuses et comprend aussi des couches de briques superposées. La décoration principale est constituée par des arcades aveugles au niveau supérieur des parois, reprises à la base de la coupole et sur son tambour, rappelant les motifs décoratifs des écoles architecturales de la Morava et de Valachie. Une particularité de la construction réside dans la série de petits piliers porteurs de trompes, sur lesquels s'appuie la coupole. Les fresques à l'intérieur de l'église et dans le sanctuaire (1608), suivant un répertoire iconographique correspondant à l'Interprétation de Dionysios, sont marquées par leur 
esprit novateur. Elles présentent des ressemblances stylistiques avec des ensembles du Mont-Athos et s'inscrivent dans le cadre des créations de l'atelier qui, en 1605, avait achevé les fresques du monastère de Piva au Monténégro, où est attestée par ailleurs la présence de peintres grecs. Les fresques du narthex (1654), d'un caractère plus conservateur, émanent de l'atelier grec qui, en 1647, a réalisé la peinture murale de l'église des Apôtres Pierre et Paul à Tutinje de Sandžak (Novi Pazar), ainsi que celle du narthex de la Naissance du Christ à Arbanassi, en Bulgarie (1649). La haute iconostase baroque qui ferme complètement le sanctuaire fut achevée plus tard, en 1776, par Paul et Anton Rezner et peinte par Teodor Kračun ; elle sera détruite pendant la deuxième guerre mondiale. Les ailes à trois étages des cellules présentent les caractéristiques d'une variation du baroque du XVIII ${ }^{e}$ siècle. L'architecture de l'ensemble, avec l'église principale comme élément synthétique dominant, a certainement utilisé comme modèle la tradition du Mont-Athos. Tous ces éléments exercent une influence sur les maçons du XVIII ${ }^{e}$ siècle qui vont en faire des modèles pour la construction de nouvelles églises dans les monastères ou des églises paroissiales (monastère de Privina Glava, Novi Jazak et Mala Remeta, même si leur riche décoration architecturale vient d'Europe occidentale).

Les monastères de Fruška Gora vont constituer les centres spirituels et culturels de réception et de diffusion des éléments européens du baroque, dont l'intégration a été la tendance prédominante dans l'évolution de l'art et de l'architecture traditionnels en Serbie. Les rénovations énergiques dans le style baroque commencent dans les églises des monastères, dans le premier quart du XVIII ${ }^{e}$ siècle, pour s'achever à la fin du siècle quand les nouvelles églises se substituent aux anciennes dans les monastères de Šišatovac, Staro Hopovo, Privina Glava, Mala Remeta et Novi Jazak. Il y a imbrication des éléments traditionnels byzantins avec les éléments architecturaux baroques. Les influences novatrices se révèlent dans les clochers élevés érigés à côté d'anciennes ou de nouvelles églises, mais aussi dans la taille importante des ailes des cellules qui donne aux ensembles monastiques une allure de fortification. De grandes baies se substituent aux petites fenêtres étroites, élément important de la transformation des rapports à l'espace, au même titre que les nouveaux effets d'éclairage. Les murs séparant le narthex de la nef principale sont démolis, les entrées sont élargies. De nouvelles coupoles, hautes, recouvertes de tuiles, sont construites sur les anciennes, en harmonie avec celles des clochers. Dans les monastères de Kuveždin et de Vrdnik le socle traditionnel est entouré de parements de forme classicisante.

Cette entreprise de " transformation » est, en premier lieu, due à des maçons allemands, qui contribuent à la formation d'une " école » locale par des artisans serbes. Certains des maîtres sont des Valaques, « sujets turcs ", venant de Langa en Épire (nouvelle église de Mala Remeta, ailes de cellules à Novi Jazak et à Fenek). C'est la première fois, par ailleurs, que des ingénieurs militaires diplômés comme, par exemple, le lieutenant Pavle Dimitrijević, participent à la conception des plans de monastères. Juste après la fin de la domination ottomane, des commerçants et des artisans spécialisés (maçons, peintres, orfèvres) venant de la ville valaque de Moschopolis en Albanie du Sud, s'installent dans les villes de l'Empire des Habsbourg, notamment après la destruction de leur ville en 1769.

Les véritables défenseurs de l'introduction du baroque européen dans l'art serbe sont les membres de l'aristocratie locale et de la bourgeoisie aisée, qui jouent le rôle principal dans l'amélioration des conditions de vie des orthodoxes au sein de l'Empire autrichien. C'est eux qui financent la construction de grands édifices, renouant avec la tradition 
médiévale de la donation afin de prouver non seulement leur conscience nationale et religieuse, mais aussi leur puissance économique. Le monastère de Chilandari, par l'intermédiaire du Patriarcat de Peć, jouit également de ces généreuses donations, et c'est par ce biais que vont s'y immiscer les éléments du baroque européen.

L'iconographie, jusqu'à la fin du XVIII ${ }^{e}$ siècle, est exercée par des peintres préparés de façon élémentaire, qui se déplacent et travaillent pour les donateurs, les moines et les higoumènes des monastères. Une figure importante est celle de Stanoje Popović, formé à la peinture dans le monastère de Šišatovać. Son œuvre, comportant les icônes de l'iconostase du monastère de Kuveždin, des icônes dans les monastères de VrdnikRavanica (1743), Šišatovac (1746), Privina Glava (1747), recouvre pratiquement la tranche chronologique située entre la première période postbyzantine et l'apparition du baroque.

Les peintres qui vont jouer un rôle décisif dans la diffusion du nouveau style font partie du cercle d'artistes formés en Ukraine, à la Lavra de Kiévo-Petchersk et à l'Académie de Vienne; il s'agit, en premier lieu, des Russes J. Vailijević et V. Romanović, suivis d'une longue série d'artistes serbes comme D. Balević, J. Halkozović, V. Ostojić, S. Tenecki, A. Janković, T. Gologlavac, T. Kaun, J. Orfelin et G. Obić. Pendant la même période, avec l'élargissement du répertoire iconographique, les iconostases deviennent plus grandes et prennent un caractère monumental, s'imposant à l'intérieur des églises, avec leur décoration sophistiquée en bois sculpté et rehaussé d'or, se substituant pratiquement à la peinture murale. Ce phénomène aura une suite et les exemples les plus caractéristiques en sont les monastères de Kuveždin et de Vrdnik. Dans ces monastères, la peinture des iconostases et les fresques sont dues à P. Simić et D. Avramović, formés à l'Académie de Vienne, qui vont façonner le goût des donateurs de Fruška Gora dans l'esprit du romantisme primitif, en exaltant les modèles représentés par des princes historiques, notamment de la famille des Nemanides, en introduisant le courant des Nazaréens au milieu du siècle.

\section{Le monastère de Horezu en Roumanie}

La Valachie a connu, en 1462, le même sort que Constantinople. La Moldavie devenue État indépendant au XIV ${ }^{e}$ siècle, atteignit son apogée territoriale et culturelle au moment des campagnes de Stefan le Grand (1457-1504) et de Peter Rares (1527-38, 1541-46) contre les Ottomans. Les principautés danubiennes, pourtant, ne devinrent jamais des provinces ottomanes intégrées à l'Empire. La domination ottomane s'exerçait par le biais du gouvernement de princes chrétiens, sélectionnés parmi les familles puissantes du pays. Le règne de Suleyman $\mathrm{I}^{\text {er }}$ le Législateur sera marqué par une période de prospérité, pendant laquelle les arts furent cultivés avec un goût raffiné. De nouvelles églises sont érigées, les monastères se multiplient et dans leurs ateliers on étudie et copie les textes anciens. Or, après l'échec de la "coalition de la Croix contre le Croissant» (comme on appelle l'alliance patriotique du Moldave Dimitri Cantemir et du Valaque Constantin Brancovan avec Pierre le Grand) le gouvernement ottoman a confié l'administration des provinces danubiennes exclusivement aux Grecs qui venaient du Phanar de Constantinople. Les gouverneurs phanariotes ont introduit dans les principautés les mœurs de Byzance et ont fortement contribué à l'essor culturel, notamment dans les classes sociales élevées.

Le monastère de Horezu a été fondé en 1690 et a profité des généreuses donations du prince Constantin Brancovan. Celui-ci a contribué personnellement, comme d'autres membres de sa famille (descendant des Cantacuzènes) à la reconstitution d'un grand 
nombre d'ensembles monastiques et d'églises en Valachie, dotés d'une riche décoration murale, de somptueuses iconostases en bois sculpté ou en pierre. Le dynamisme de cette créativité artistique a exercé sur nombre de notables et de prélats de la période une influence, contribuant à façonner un style particulier en architecture, peinture et décoration, connu sous le nom d'« art Brancovan ». L'école de peinture du monastère de Horezu fut la plus importante de Valachie au cours du XVIII siècle.

91 L'église principale du monastère, consacrée aux saints Constantin et Hélène, fut érigée en 1690-92. L'aménagement de l'espace suit un axe est-ouest, et l'église est située dans un paysage de collines boisées, au centre d'une enceinte presque parfaitement rectangulaire. Les ailes de cellules, à deux étages, sont dotées de larges balcons maçonnés, couverts de lourdes arcades en pierre. Elles entourent l'église au Nord, au Sud et à l'Ouest. L'entrée du monastère se trouvait à l'origine au milieu du côté occidental de l'enceinte, avec une chapelle annexe au-dessus. Elle fut transformée en réfectoire oblong, avec une voûte en berceau, et l'entrée fut transférée sur le mur méridional, au pied du grand clocher.

L'église, caractérisée par de larges murs en pierre de taille, comprend trois conques avec des absides à sept pans, des absidioles latérales du côté oriental. L'espace central est éclairé par une coupole avec un tambour extrêmement haut, percé d'ouvertures étroites et de multiples arcades. Le large narthex est couvert de voûtes en plein cintre et de voûtes d'arêtes, alors qu'une coupole, également haute, couvre l'espace central, prenant appui au sud de la nef principale sur un couple de piliers. Dans la partie occidentale du narthex se trouve une galerie ouverte, surmontée de voûtes aveugles, et dont le portique est couvert. L'église reprend un type connu depuis longtemps dans l'architecture roumaine médiévale, celui de l'église du monastère de Curtea de Argeş, construite par Nesagoe Besarab (1517). Ce type est ici réalisé sur la base d'une conception et d'un programme différents: les proportions sont modifiées, le narthex se rétrécit et devient directement fonctionnel (il comporte les tombes princières de la famille des donateurs). L'église conserve la plasticité des volumes et l'élégante décoration en pierre sculptée des surfaces extérieures, les rubans torsadés sculptés, les arcades dentelées byzantines, autour d'emprunts au langage stylistique de la période précédente. Le maître maçon et tailleur de pierre était Vucashin Caragea.

On peut également relever des similitudes dans la décoration murale, où les thèmes picturaux s'adaptent au caractère particulier de chaque bâtiment et de chaque unité spatiale. La paroi méridionale du narthex extérieur est recouverte d'une représentation gigantesque de la Seconde Parousie. Dans ses voûtes aveugles prédomine le pittoresque avec des paysages, des scènes de la tradition populaire locale. La zone basse du narthex intérieur est illustrée de représentations en pied de Constantin Brancovan, de sa femme et de leurs onze enfants. Dans le narthex intérieur s'étalent des portraits des autres membres de la Maison Brancovan. À l'intérieur de la nef centrale se retrouve le répertoire iconographique traditionnel. La peinture est marquée par la finesse de figures bien proportionnées, au tracé énergique, traitées dans des couleurs aux résonances profondes et chaudes. Les traits principaux de ce style s'expriment de façon parfaite dans la peinture des voûtes de la nef centrale, où sont représentés les thèmes symboliques du Pantocrator, du Christ Emmanuel et de l'hymne Acathiste, d'une facture noble et fine. Le répertoire iconographique de l'église, pour l'essentiel symbolique et dogmatique, constitue un véritable manifeste de l'orthodoxie ${ }^{48}$. La peinture de l'église a été réalisée dans la période 1693-94 par le peintre grec Constantin, avec l'appui des collaborateurs locaux Jean, Stano, Neagoe et Joachim ${ }^{49}$. Ils sont parvenus à combiner des éléments du 
décor oriental influencés par le baroque et le maniérisme avec des éléments de l'art byzantin. Dans le monastère Horezu s'affirme le style de l'illustre école post-byzantine de peinture de Moldavie et de Valachie, qui va briller jusqu'au XIX ${ }^{\mathrm{e}}$ siècle. L'iconostase en bois sculpté est d'une qualité exceptionnelle et (ainsi que l'iconostase de l'hôpital qui en est bien proche) a servi de modèle à une série d'iconostases pour les églises des Balkans du Centre et du Nord.

Pendant la même période sont également érigés d'autres bâtiments, comprenant le palais du prince, les ailes des cellules monastiques à deux étages, le réfectoire, les cuisines, les entrepôts et les espaces de production. De même, dans l'ensemble monumental du monastère de Horezu, sont comprises d'autres constructions contemporaines, érigées par d'autres membres de la famille princière : ainsi la chapelle annexe, destinée à la prière, à l'étage de l'aile occidentale, peinte avec la même finesse. La Bolnica (hôpital), un ensemble séparé, plus petit, comportant une église, fut construite grâce à la princesse grecque Maria, épouse du prince, ainsi que les ermitages de Saint-Stéphane, construit comme une micrographie du monastère, avec une église à trois conques et des Saints-Apôtres, qui reproduit les chapelles rectangulaires de la cour.

La réalisation d'un ensemble monumental des dimensions de Horezu, requiert la concentration d'un grand nombre d'artistes, architectes, peintres, décorateurs, orfèvres, brodeurs, graveurs, etc. Indépendamment de leur nombre et de leur origine, le produit de leur art se présente toujours comme le résultat du travail collectif d'un groupe uni par un esprit artistique commun et une grande exigence de qualité, marqué par une profonde connaissance du dogme de l'orthodoxie, qui a pour but une expression idéologique particulière de l'identité nationale. Tous ces éléments font sans aucun doute du monastère de Horezu l'exemple le plus représentatif de son époque.

Le monastère a passé des moments difficiles pendant les guerres turco-autrichienne et russo-turque (1716-18 et 1789). Grâce aux travaux de conservation et de restauration de l'ensemble (1950-60), qui sont parvenus à restituer l'essentiel de sa forme initiale, il a été intégré au patrimoine culturel mondial de l'UNESCO en 1993.

\section{Illustrations}


Mont-Athos, monastère de Docheiariou, $\mathrm{X}^{\mathrm{e}}$ siècle

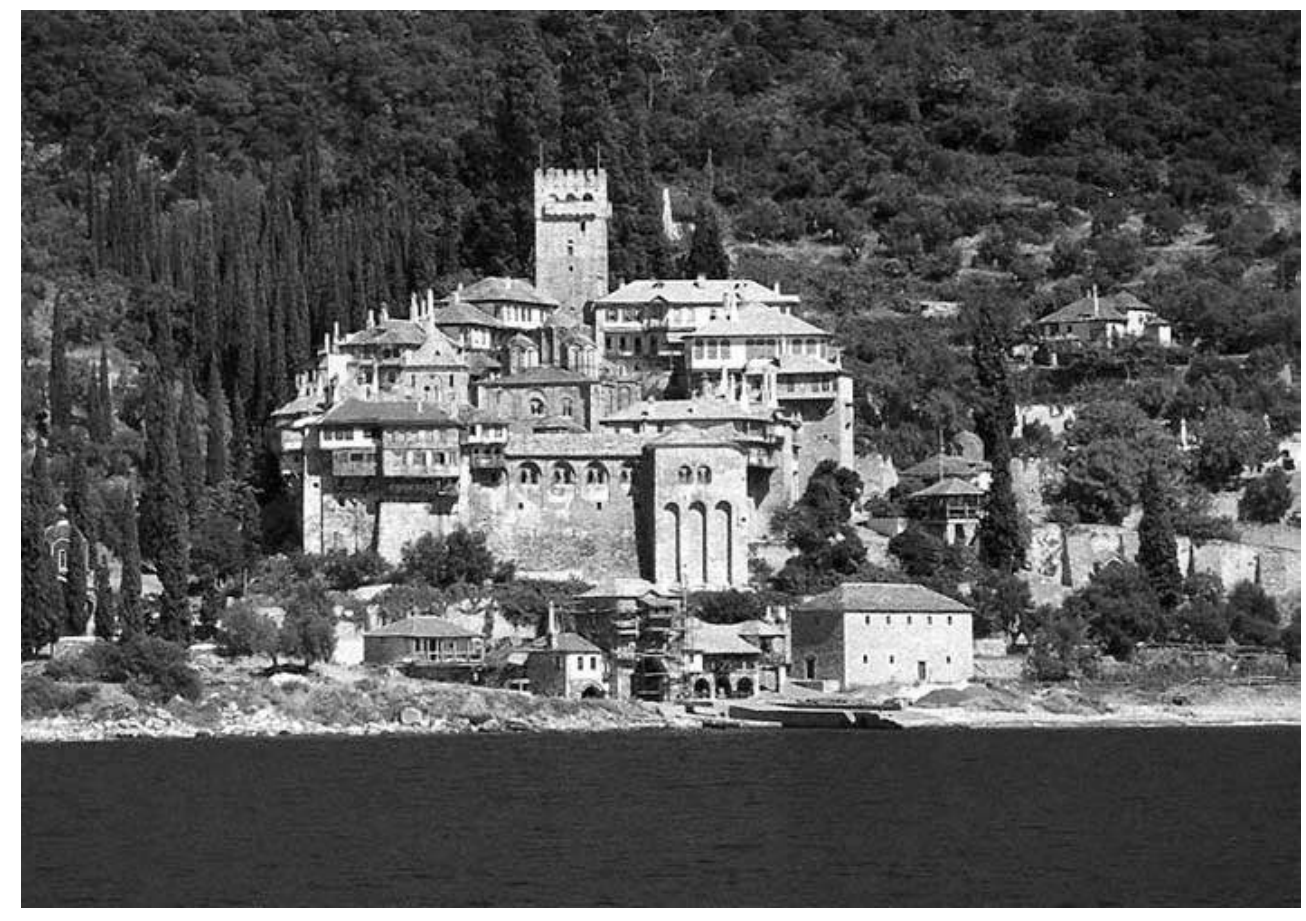

Météores, monastère de Varlaam, 1517

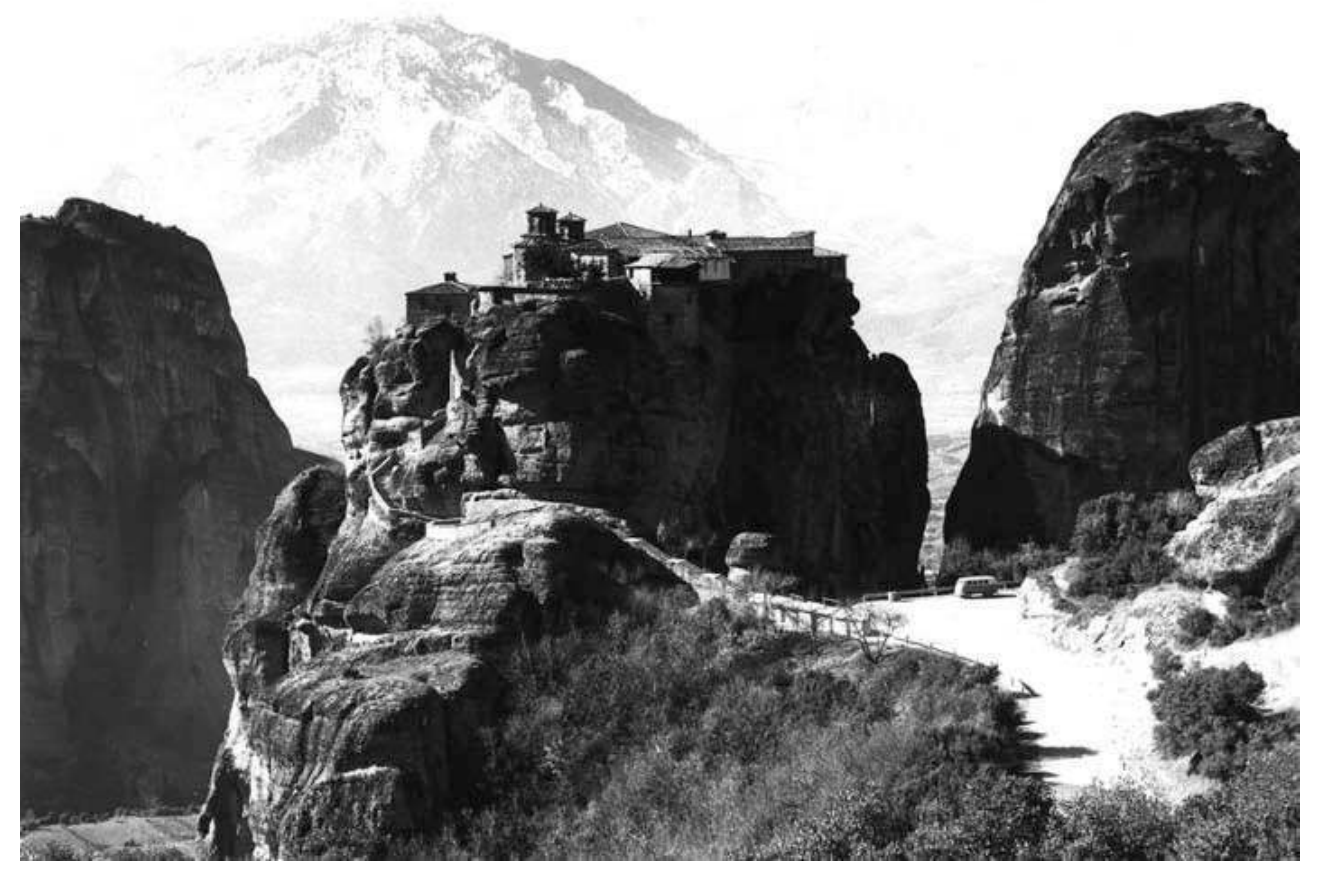


Ioannina, monastère du Prodrome, 1506/07

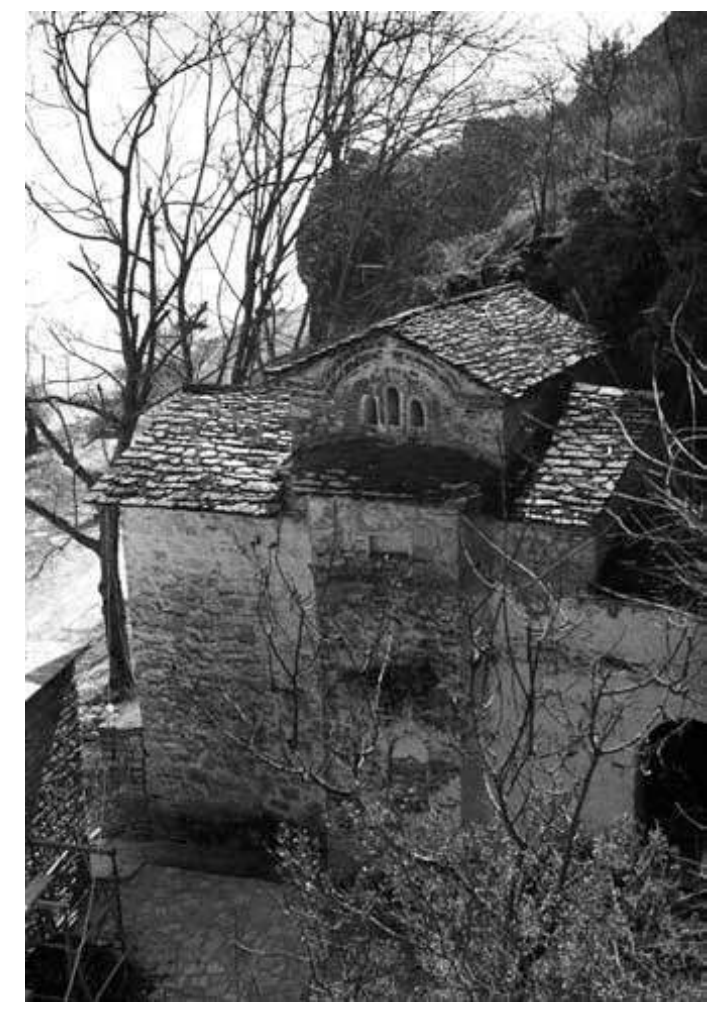

Fruška Gora, la nef du monastère de Novo Hopovo, 1576

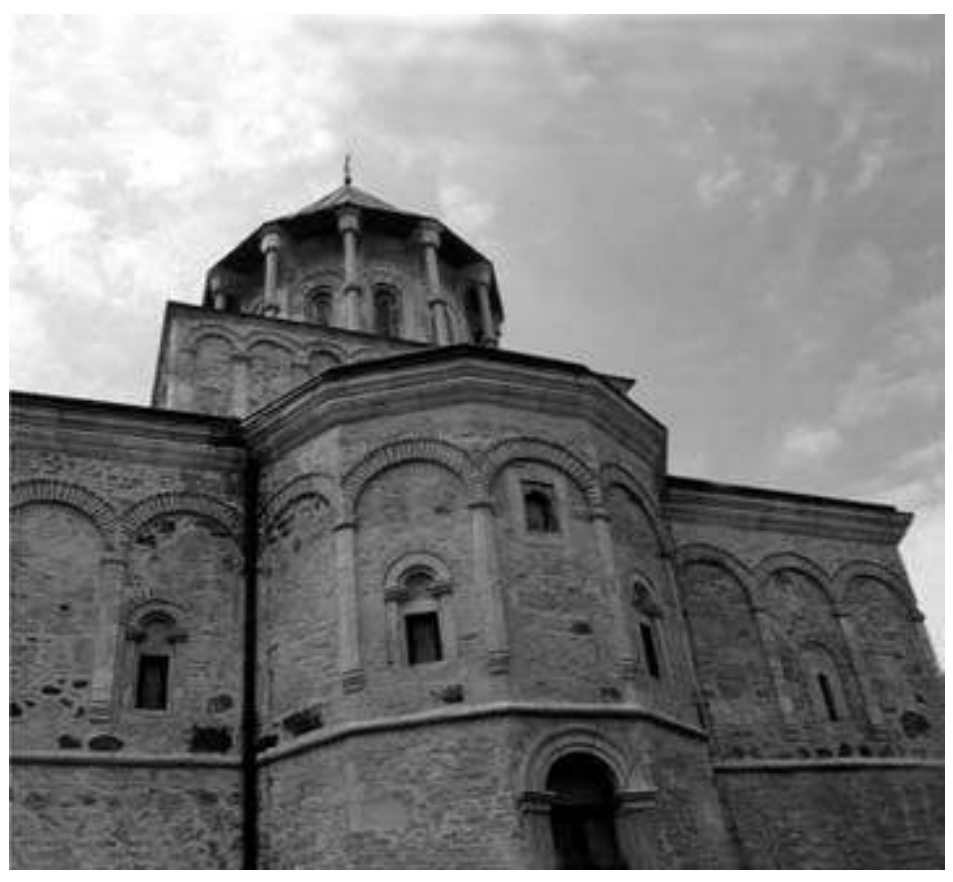


Bačkovo, le monastère de la Mère de Dieu (Pétritsonissa), 1604

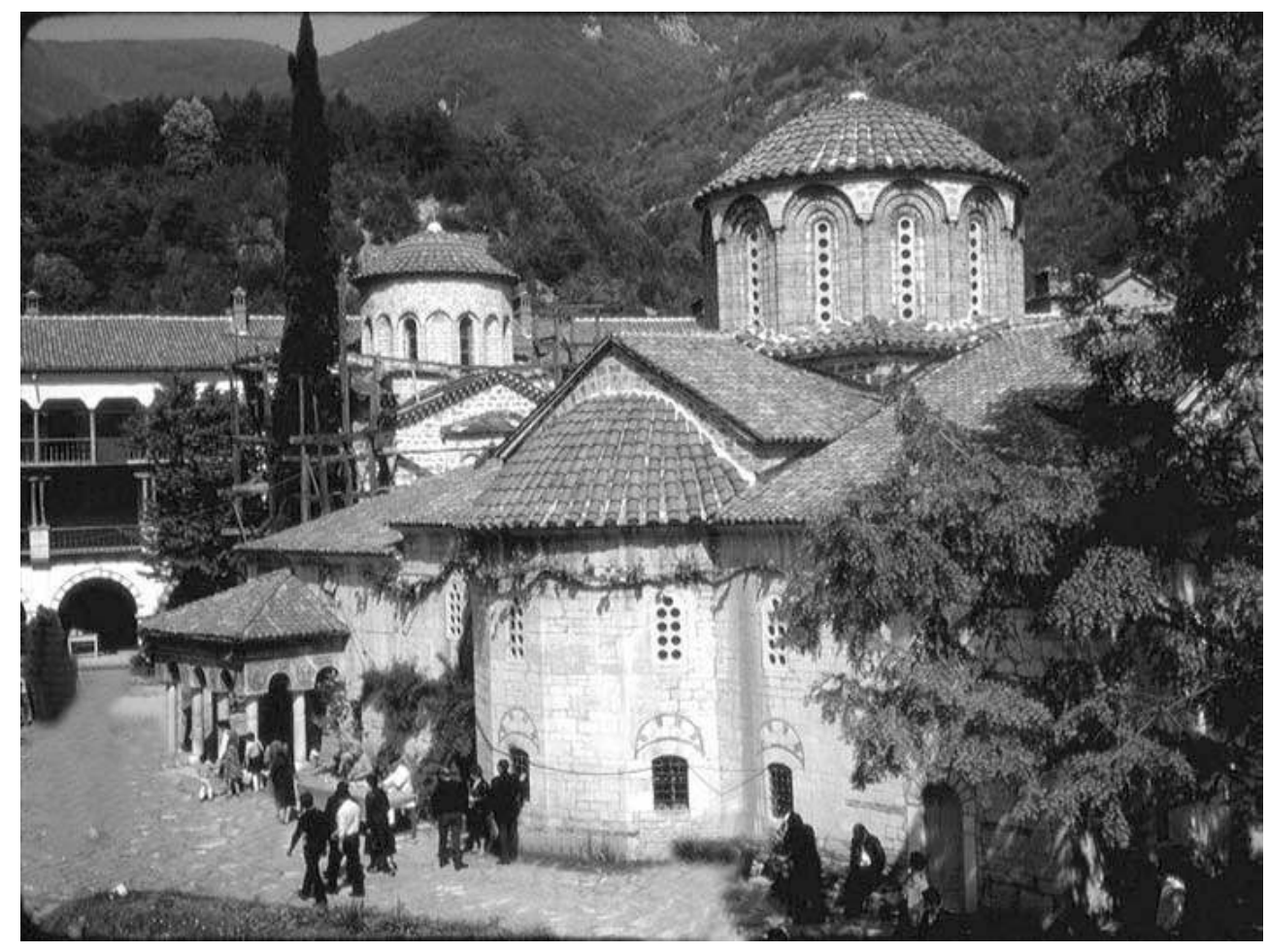

Voskopojë, église de la Dormition de la Vierge, 1699

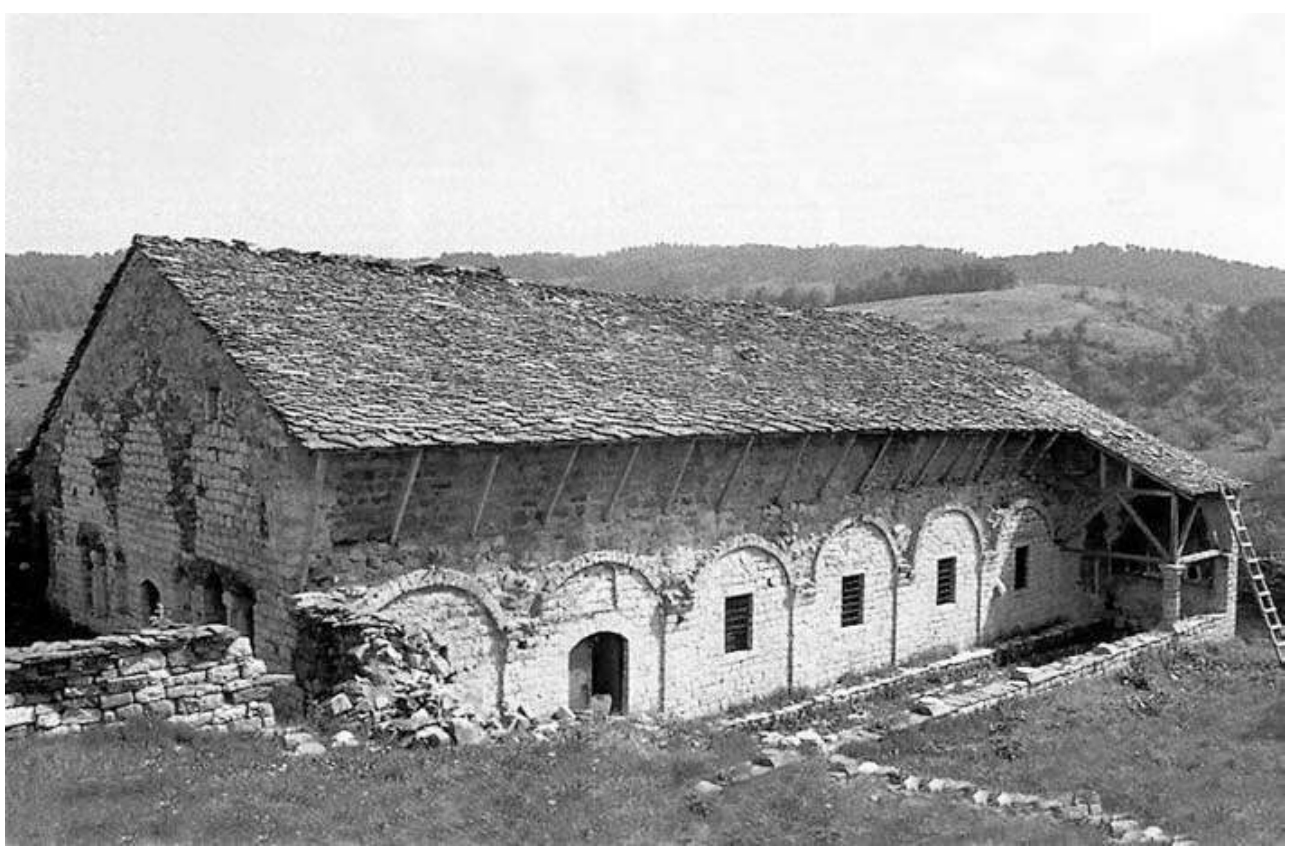




\section{Le monastère de Rila}

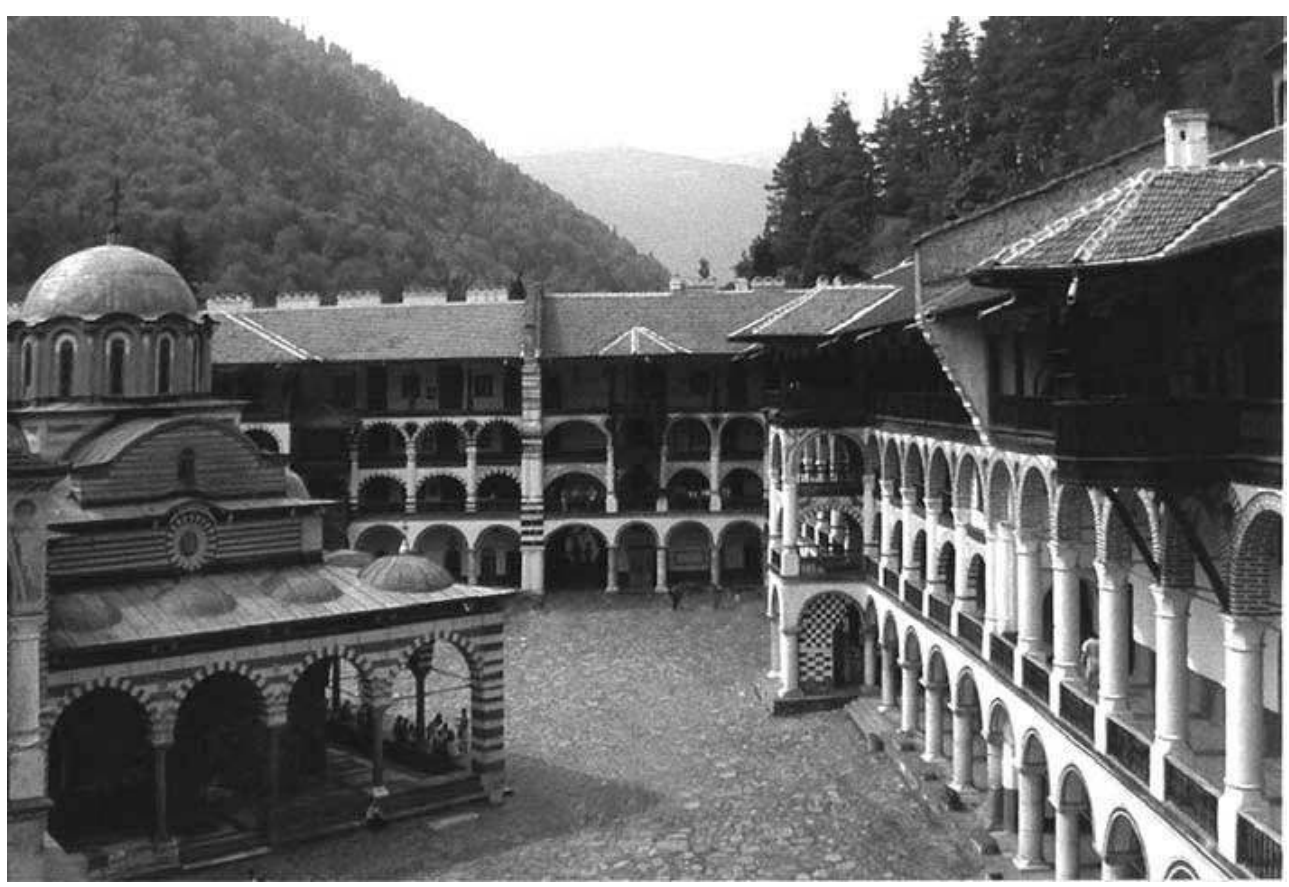

\section{BIBLIOGRAPHIE}

\section{Généralités}

Actes du Premier Congrès International des Études Balkaniques et Sud-Est européennes. Arts-Communauté et diversité de l'art des pays balkaniques (XVI ${ }^{e}$ siècle-début du XVIII ${ }^{e}$ siècle, t. II, Sofia, 1969.

Chatzidakis M., « Aspects de la peinture religieuse dans les Balkans (1300-1500) », in : Birnbaum H. et Vryonis Sp. Jr. (éd.) Aspects of the Balkans. Continuity and Change, Paris, 1972, p.177-197.

Grabar A., L'art du Moyen Âge en Europe Orientale, Paris, 1968.

Medaković D. (éd.), Le baroque de l'Europe occidentale et le monde byzantin, Belgrade, 1991.

\section{Albanie}

Ikonen aus Albanien. Sakrale Kunst des 14. bis 19. Jahrhunderts (herausgegeben von B. Öhrig), Münich, 2001.

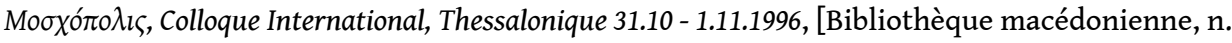
91], Thessalonique, 1999.

Drishti Y. et Çika L., Icons of Berat, Tirana, 2003.

Drishti Y., The Byzantine and Post-Byzantine Icons in Albania, Tirana, 2003. 
Thomo P., Kishat Pasbizantine në Shqipërinë e Jugt, Tirana, 1998.

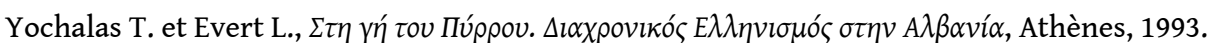

\section{Bulgarie}

Angelov V., Bălgarska monumentalna dărvorezba, XIV-XXv., Sofia, 1992.

Berbenliev P., Arhitekturnoto nasledstvo po Bălgarskite zemi, Sofia, 1987.

Božkov A., Bălgarsko izobrazitelno izkustvo, Sofia, 1988.

Vasiliev A., Bălgarski văzroždenski majstori, Sofia, 1965.

Kiel M., Art and Society of Bulgaria in the Turkish Period, Assen/Maastricht, 1985.

Koeva M., Pametnići na kulturata prez Bălgarskoto văzraždane, Sofia, 1977.

Mavrodinov N., Izkustvoto na Bălgarskoto văzraždane, Sofia, 1957.

Tschilingirov A., Die Kunst des christlichen Mittelalters in Bulgarien, Architectur-Malerei-Plastik, 4.bis 18. Jahrhundert, Berlin, 1978.

\section{Grèce}

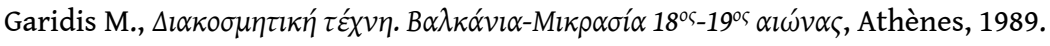

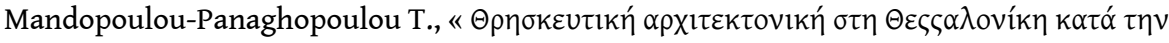

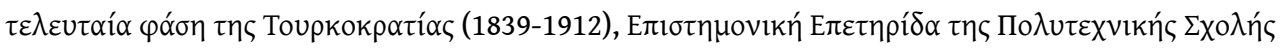

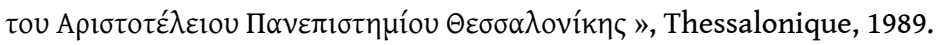

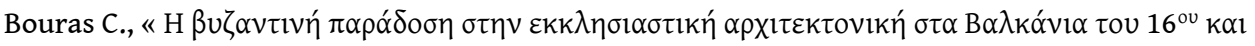

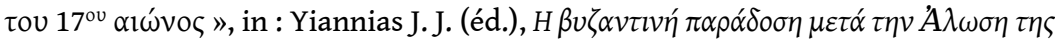

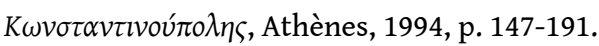

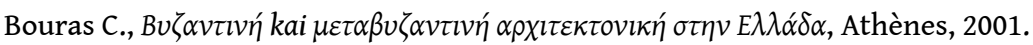

Mylonas P., Pictorial Dictionary of the Holy Mountain Athos, vol. I, part I (Atlas-Topography and Historical Architecture), fasc. III (Maps and Plates), Berlin, 2000.

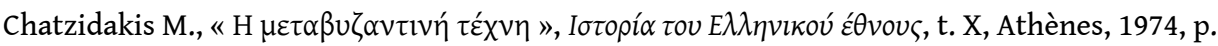
410-437 ; t. XI, Athènes, 1975, p. 266-269.

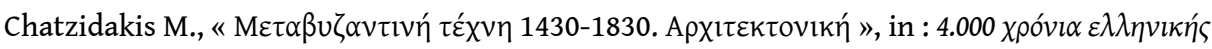

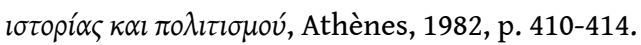

\section{Macédoine}

Boyadjiévsk i K., Le trésor artistique de la Macédoine, Skopje, 1984.

Ćornakov D., Macedonian wood-carving, Zagreb, 1987.

\section{Roumanie}

Drăguț V., La peinture murale de la Moldavie, XVe - XVI siècle, Bucarest, 1983

Grabar A., Les fresques de la Roumanie, éd. Unesco.

Miclea I. et Florescu R., Hurezi, Bucarest, 1989.

Miclea I., Doulce Bucovine, Bucarest, 1976. 


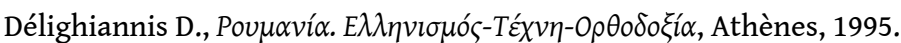

\section{Serbie et Monténégro}

Kulić B. et Srećkov N., The Monasteries of the Fruška Gora, Novi Sad, 1994.

Mijović P., Art Treasures of Montenegro, Belgrade, 1980.

Popović S., Krst u krugu. Arhitektura manastira u srednovekovnoj Srbii, Belgrade, 1994.

Šuput M., Srpska arhitektura u dova turske vlasti 1459-1690, Belgrade, 1984.

Šuput M., Spomenici srpskog crkvenog graditeljstva XVI-XVII vek, Belgrade, 1991.

\section{NOTES}

1. Raya (turc)=troupeau

2. C'est de cette façon que s'explique la conservation des églises byzantines dans certaines grandes villes, comme, par exemple, à Berat: la ville-forte fut soumise à Mehmed II le Conquérant en 1417. Par la suite, celui-ci promulgue un berat (document impérial validant l'attribution de dignités ou de privilèges), qui se trouve à l'origine du changement même du nom de la ville qui perdit son ancien nom de Vélagrada pour celui de Berat. Par ce berat il accordait aux habitants de la ville la liberté de religion, de culte, et de mœurs ainsi que d'autres privilèges, comme l'exemption fiscale, à condition de protéger le port important d'Avlona en cas de danger. Grâce à cette décision, les habitants ont eu le droit de rester dans leurs quartiers à l'intérieur du château, en conservant leurs anciennes églises.

3. Dans ces cas les fresques byzantines ou les mosaïques sont couvertes d'une épaisse couche de mortier qui est peint d'une décoration végétale, conformément aux injonctions de la religion islamique interdisant la représentation des êtres vivants comme cela s'est passé, par exemple, au monastère de Chora à Istanbul, transformé en Kariye Camii.

4. Pour une interprétation des facteurs socio-économiques du développement de l'art chrétien dans les Balkans pendant la période ottomane voir: M. Kiel, Art and Society of Bulgaria in the Turkish Period, Assen/Maastricht, 1985 ch. V, p. 56-142.

5. $\Sigma \tau \alpha u \rho \circ \pi \eta ́ \gamma ı$ = église dépendant exclusivement du Patriarche qui, au moment de son inauguration, envoie la croix qui doit y être déposée.

6. Les Vies des néo-martyrs, écrites en principe en grec, mais aussi dans toutes les autres langues balkaniques, furent parmi les textes les plus importants de cette période et ont joué un rôle de propagande chrétienne dans tout le monde orthodoxe. Ils ont été à plusieurs reprises copiés et imprimés à Venise, dans les imprimeries grecques de Roumanie, à Istanbul ou à Vienne. Ces textes ne reposent pas sur une base nationale : les néo-martyrs sont des Serbes, des Bulgares, des Albanais, des Roumains ou des Grecs, ils n'admettent pas davantage de modèle social : certains néo-martyrs viennent de familles aisées, d'autres sont pauvres, certains sont cultivés, d'autres illettrés, paysans, bergers, ouvriers. La typologie reflète clairement le modèle byzantin des Vies des saints, à une différence près : ici l'ennemi n'est plus l'idolâtre païen, mais le Turc ottoman.

7. Dans plusieurs églises moldaves (VoroneŢ-1550, Riska-1552, Humor-1535, Moldoviţa-1537) les Arméniens monophysites sont placés parmi les réprouvés dans la représentation du Jugement dernier au même niveau que les Turcs, les Juifs et les autres hérétiques.

8. Corporations organisées strictement selon la spécialité exercée et la hiérarchie.

9. On donne à titre indicatif les exemples des voûtes aveugles qui couvrent les églises des monastères du Pantocrator à Daou de Pentéli en Attique (1565), Agnountos en Grèce continentale (environ 1700), Jovan Bigor (1800) en République de Macédoine, le narthex du monastère Saint- 
Georges d'Arma en Eubée (1637), mais aussi le narthex extérieur (milieu du XVI ${ }^{\mathrm{e}}$ siècle) de l'église principale du monastère de Gračanica au Kosovo (reconstruite). En Bulgarie, ces voûtes sont encore plus répandues: les églises principales des monastères des Saints-Anargyres à Kuklena (fin XVII ${ }^{\mathrm{e}}$ siècle) près de Sténimachos (Assenovgrad), de la Transfiguration (1835) à Veliko Tirnovo, de Devieski (1848) à Gabrovo, et de la Mère de Dieu à Kievo de Varna. De même, dans les églises des Archanges (1760) à Arbanassi, de Saint-Nicolas à Elena (1805), de Sainte-Kyriaki à Batak (1813), ainsi que les chapelles annexes au monastère de Rila (Saint-Jean-Prodrome, SaintsSavas et Syméon, Saint-Jean Chrysostome, Saints-Archanges et Saint Ivan Rilsky, 1817-1820).

10. A. Grabar, L'art du Moyen Âge en Europe Orientale. L'art dans le monde, Paris, 1968, p.87.

11. Le chrétien islamisé Mehmed Pasha Sokolović, troisième grand vizir de la Porte, fit monter sur le trône patriarcal son frère chrétien Makarie. À la suite de cet événement, le Kosovo et la Metohija retrouvèrent, durant les deux siècles suivants, leur place de centres culturels et politiques des Serbes.

12. A. Grabar, Les fresques de la Roumanie, éd. Unesco, p. 5.

13. Cette représentation constitue, d'une part, une réaction de défense contre la peur provoquée par le Grand Turc, mais aussi une offensive contre les «blasphémateurs» catholiques protégés par la maison impériale de l'Autriche voisine qui favorise pendant cette période l'union des orthodoxes de Transylvanie avec Rome. D'autre part, les tendances au rapprochement avec le protestantisme sont également condamnées.

14. En Crète, sous la domination vénitienne, il était possible d'accéder à l'art italien, puisque les églises latines étaient décorées d'œuvres de Veronèse, du Titien, de Raphaël, de Vivarini entre autres. Plusieurs maisons de nobles vénitiens étaient également décorées de tableaux de peintres occidentaux et disposaient d'éditions illustrées de livres ou de manuscrits enluminés. À côté des gravures sur cuivre largement répandues, les peintres crétois étudiaient l'art de l'Occident à l'occasion de voyages en Italie. Dans la seule deuxième moitié du XVI ${ }^{\mathrm{e}}$ siècle, soixante-trois artistes connus sont mentionnés dans la ville de La Canée.

15. Le mouvement des Uniates a adopté et mis en avant cet élément architectural, dans son effort d'attirer des fidèles de l'Église orthodoxe: l'iconostase, arrivant jusqu'au plafond de l'église, chargée d'une décoration baroque en bois sculpté et d'une multitude d'icônes de style occidental, constitue le trait caractéristique d'un grand ensemble d'églises de Transylvanie des $\mathrm{XVIII}^{\mathrm{e}}$ et $\mathrm{XIX}^{\mathrm{e}}$ siècles, où les pressions assimilatrices de l'église catholique se sont faites assez fortes.

16. Le succès de ce type serait dû, d'après les différentes interprétations, à la tentative d'un retour conscient de l'Église orthodoxe aux sources originelles «antiques » sous l'action du patriarche Kallinikos (1757-1762) ou encore à la construction de l'église patriarcale d'Istanbul (1720) selon le modèle basilical à trois nefs. Il semble, pourtant, qu'il y ait eu d'autres facteurs, comme le besoin de pouvoir assurer une présence nombreuse des membres de la communauté à la messe, ainsi que la simplicité de construction à partir de matériaux facilement accessibles.

17. Les sujets mythologiques à valeur symbolique sont tirés des manuscrits illustrés, largement répandus au $\mathrm{XVI}^{\mathrm{e}}$ siècle, contenant les Oracles de l'empereur de Byzance Léon VI le Sage, de l'archevêque de Patara Méthodios, et des Visions du prophète Daniel. Le Physiologos, avec ses messages édifiants, traité où l'on a cru voir le "symbolisme chrétien de la nature ", a été largement diffusé parmi les populations slaves pendant la période médiévale, grâce à des traductions. Cette diffusion continue pendant la période post-byzantine.

18. Dans les hôtelleries des monastères, où les dignitaires et les représentants des corporations étaient hébergés, la décoration (peinture ou bois sculpté) reproduit les pièces de réception des maisons aristocratiques de la période. Ces espaces sont d'habitude couverts par des kubbe, terme turc désignant des coupoles aveugles décoratives surbaissées, tout comme dans les nefs centrales des églises. 
19. Le terme de « Renaissance balkanique » est en usage depuis longtemps, en particulier dans la bibliographie slavophone et albanophone, mais il n'est pas unanimement accepté par les chercheurs, l'argument le plus important étayant son rejet est l'écart qu'il y a avec le moment où le terme de «Renaissance culturelle» prend un véritable sens chez les différents peuples balkaniques.

20. En effet Manolis Chatzidakis fait remarquer qu'on connaît plus de sept cent cinquante peintres Grecs au XVIII ${ }^{\mathrm{e}}$ siècle, soit le double du siècle précédent. D'autre part, les chiffres de la deuxième moitié $d u$ XVIII ${ }^{\mathrm{e}}$ siècle sont deux fois plus élevés que ceux de la première moitié du siècle.

21. Ces tendances contradictoires sont représentées par les écrits de deux peintres de l'époque.

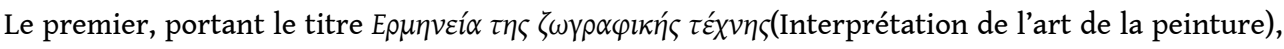
a été écrit au Mont-Athos, aux alentours de 1730, par le moine Dionysios, qui prônait un retour

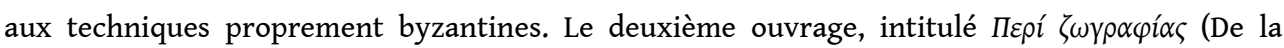
peinture) est écrit dans les Iles ioniennes, en 1726, par Panagiotis Doxaras, qui enseigne la peinture à la façon de Véronèse. Doxaras a également traduit en grec le traité de Léonard de Vinci sur la peinture.

22. Hayat (littéralement, en turc, seuil d'une maison) : constructions en saillie déterminant un espace semi-ouvert qui laisse passer le soleil et le vent.

23. Sahne (terme d'origine persane) : constructions en saillie fermées, d'où l'on peut regarder la rue sans être vu; c'est l'équivalent du « $\delta \rho v ́ \varphi \alpha \kappa \tau o \varsigma$ » des Byzantins.

24. À savoir dans l'église byzantine principale à Karyès, chef-lieu du Mont-Athos.

25. Il est significatif que le synode de l'Église russe, convoqué à Moscou à l'époque du tsar Ivan IV le Terrible (1551) afin d'instaurer les règles de l'hagiographie se soit basé sur la pratique des peintres crétois (Tome Stoglav, comprenant cent chapitres).

26. Nul autre n'arriva comme lui au Patriarcat de Peć à combiner dans une conception artistique cohérente les instructions des peintres serbes du XVI ${ }^{\mathrm{e}}$ siècle et celles de l'école crétoise, en y ajoutant un élément expressif. Son art s'oriente de plus en plus vers l'utilisation de couleurs claires et de proportions classiques harmonieuses, éléments qui vont ouvrir la voie à un grand nombre de peintres jusqu'au début du XVIII ${ }^{\mathrm{e}}$ siècle.

27. Au monastère de Chilandari, en particulier, se trouve aujourd'hui la plus grande collection de manuscrits et livres imprimés slaves (XII ${ }^{\mathrm{e}}-\mathrm{XVII}^{\mathrm{e}}$ siècles).

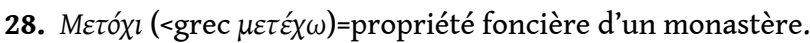

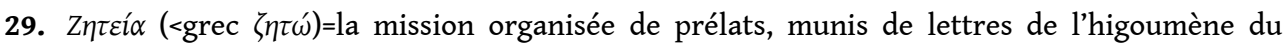
monastère ou du Patriarcat, dans le but de s'assurer une aide financière de la part des puissants de l'époque.

30. Les modèles les plus proches de l'iconostase en bois sculpté de Bačkovo se trouvent au monastère de Saint-Jean-Prodrome à Ipishia (Šipska) de Moschopolis (Voskopojë), datant de la même époque et dans les monastères d'Épire: Varlaam et Saint-Stéphane aux Météores, la Sainte-Trinité Drakotrypas dans le Pinde méridional, l'Assomption Chrysovitsas à Metsovo, la Naissance de la Mère de Dieu à Rapsista de Ioannina, Saint-Pantéléimon dans l'île du lac de Ioannina, Vélas à proximité de Ioannina, Saint-Georges Drosopighis, Evangélistrias Kypselis, Seltsou et Saint-Mercure à Arta. À retenir également: le monastère de Phlamourion du Pilion (réalisé par des Épirotes) et de Sainte-Paraskévi Kokkoton (Orthys, réalisé par des Crétois, 1721).

31. L'archonte Georges avait le titre de Sloutziari à Krajova de Moldavie (dignité des principautés attribuée au responsable de l'alimentation de la cour et de l'armée), alors que son fils Constantin est devenu grand Postelnikos (dignité correspondant à celle du ministre de l'intérieur). Leur famille (dont le chef était le grand-père Georges "Grammatikos ») était originaire du village de Blasi, à Agrafa du Pinde, où ils ont financé, pendant la même période, la peinture de l'église de Saint-Jean-Prodrome (1641) et de l'église principale du monastère de la Naissance de la Mère de Dieu (1644). Les donateurs, tout comme les saints représentés dans la 
fresque sont vêtus des longs caftans brodés que portaient les princes des provinces danubiennes, comparables par leur texture aux voiles d'une iconostase du monastère de Putna (région de Suceava) ou à ceux qui se trouvent dans l'église de Sibiu (XVI ${ }^{\mathrm{e}}$-début du XVII ${ }^{\mathrm{e}}$ siècle).

32. D'après la tradition néoplatonicienne sur Jésus-Christ, les philosophes et les écrivains grecs antiques, censés avoir prédit de manière prophétique l'avènement du Messie étaient intégrés dans la thématique concernant les prophètes, les sibylles de l'ancien Testament et l'« Arbre de Jessé ». On retrouve déjà ce thème dans des églises byzantines, mais il est particulièrement répandu dans certaines églises post-byzantines de Grèce (réfectoire du monastère de Lavra au Mont-Athos, réalisé par Théophanès, en 1535, monastère de Saint-Nicolas « Philanthropinon » de l'île du lac de Ioannina, 1560), en Bulgarie (Nativité à Arbanassi, 1637), en Serbie, en Roumanie (églises de Moldavie, $\mathrm{XVI}^{\mathrm{e}}-\mathrm{XVII}{ }^{\mathrm{e}}$ siècles) et enfin en Russie. Il est considéré comme une expression de l'humanisme chrétien et un précurseur des tendances rationalistes dans les interrogations philosophiques de la pensée religieuse orthodoxe dans les Balkans.

33. $T \sigma o \rho \mu \pi \alpha \tau \zeta \eta \hat{\eta} \delta \varepsilon$ (<turc=çorbaci) on appelait ainsi les archontes, les notables riches. L'ironie de la peinture est qu'elle a été réalisée grâce au financement d'un autre $\tau \sigma o \rho \mu \pi \alpha \tau \zeta \zeta \eta^{\prime}$, le riche commerçant bulgare Vâlčo Kurtovic Čalâkov, originaire de Kopritica, qui dirigeait à l'époque la gestion du monastère.

34. Du nom de Damaskinos Stouditès, prêtre grec du XVI ${ }^{\mathrm{e}}$ siècle originaire de Salonique qui a recueilli 43 de ses discours dans un texte appelé « Thesaurus ».

35. Bigor $=$ tuf, pierre poreuse

36. Il s'agit sans doute de l'archevêque d'Ohrid Jean de Debar, désigné par l'empereur byzantin Basile II, après la conquête de l'État bulgare. Une icône du saint patron du monastère, conservée encore de nos jours, date de cette période.

37. Frćkovsky<(turc) firça=brosse/pinceau, parce que quelques maitres de la famille étaient peintres.

38. Les maîtres, eux-mêmes, ont fait leur portrait au moment du travail, comme, par exemple, dans l'église du Christ Sauveur à Skopje.

39. Michel Anagnostis, fils de Dimitrios, a renouvelé la peinture en Macédoine en introduisant des éléments d'une représentation réaliste du monde (monde végétal, ensembles architecturaux, coutumes locales) dans un style baroque. Avant 1789, il a exécuté la peinture de la nef du monastère des Apôtres Pierre et Paul Kleinou, près du village de Klinovos dans la province de Kalabaka en Thessalie. Les icônes «despotiques» de l'iconostase et la Naissance de la Vierge du château d'Elbasan (1828), lui ont valu d'être appelé l'«Albrecht Dürer » de l'Albanie. À son fils Dimitrios, portant le nom monastique de Daniel, on doit la peinture de l'abside du sanctuaire, ainsi que des portraits d'archimandrites dans le réfectoire du monastère de Bigor. En 1840, père et fils ont réalisé ensemble la peinture de la coupole et de l'iconostase de Saint-Georges à Rajčića de Debar.

40. Dičo Krstević (1819-1872) venait d'une famille de sculpteurs sur bois de Macédoine. C'était un des peintres les plus talentueux et les plus productifs : il a réalisé les fresques de diverses églises à Lazaropolje (1841) et l'église principale du monastère de Saint-Nikita à Skopje (1847), et a peint des icônes dans le monastère de Treskave à Prilep (1854), de la Mère de Dieu à Kievo (1848-1865), du Christ Sauveur (1854) et de la Mère de Dieu à Skopje (1857), de la Sainte-Trinité à Vranja (1859) et dans des églises de la région d'Ohrid (1862) et de Bulgarie du Nord-Ouest. On connaît bien son Interprétation manuscrite qu'il utilisait au cours de son travail (avec des dessins explicatifs), traduite en bulgare à partir de l'original grec (1844).

41. Les plâtriers exécutaient les décorations en plâtre ou en stuc qui, par la suite, étaient soit peintes soit couvertes de feuilles d'or.

42. Au monastère de Rila, les «Mijacki » ont travaillé sous la direction du contremaître Athanase Tagliadourou (Tagliadourou traduit l'italien intagliatore), Grec de Salonique qui, après la déclaration de la guerre d'indépendance grecque en 1821, fut vendu comme esclave à Samokov. 
En 1833, il a complété avec une grande virtuosité les parties latérales de l'iconostase de l'église métropolitaine de Samokov dont la partie centrale, œuvre du moine Antonios, avait été apportée, en 1793, du Mont-Athos. Avec son œuvre, Athanasios a créé le noyau de l'école de sculpture sur bois de Samokov, à l'épanouissement de laquelle ont par la suite contribué d'autres artistes Bulgares.

43. Les « Mijacki » venant de Dolna et de Mala Reka, Petre Filipi «Garka » originaire de Gari et les ancêtres des Frćkovsky venant de Galičnik ont appris leur art à Salonique, auprès d'Italiens, venus travailler comme charpentiers, maçons, peintres et sculpteurs.

44. L'art de David Sélénitziotis (Selenica), originaire de Vlora en Albanie, se situe à un très haut niveau et fait partie de la tendance rétrospective prônant le modèle des Paléologues, qui a pris naissance au Mont-Athos. Un exemplaire de son «Interprétation" (1711) se trouve dans le monastère de Lavra. Ses œuvres se sont répandues sur le Mont-Athos (narthex de la chapelle de Portaïtissa à Lavra, 1715), à Kastoria et à Moschopolis, avec l'aide de Christos et Constantin, et très probablement à Salonique. Les caractéristiques de son style sont, à côté des influences occidentales, le réalisme des costumes traditionnels contemporains et des instruments de musique.

45. Le village de Krimini est situé à proximité de Kastoria, en Macédoine occidentale. Il appartient au groupe de villages de la montagne de Voïos, d'où sont originaires de nombreux tailleurs de pierre, comme les illustres Zoupaniotes, de la bourgade de Zoupani (actuellement Pentalofo). L'architecte Paul du monastère de Rila était également originaire de Krimini.

46. C'est ainsi que sont interprétées les particularités architecturales des églises et des maisons fortifiées des archontes à Arbanassi, en Bulgarie. La décoration en bois sculpté de l'intérieur de ces églises est directement liée au style «Brancovan » de Valachie, mais révèle, en même temps, des éléments de la Renaissance communs avec l'école des Iles ioniennes. Par ailleurs, à Peštera, près de Philipoupolis, a été créée une école locale de maîtres ouvriers qui, en collaboration avec leurs voisins Bulgares de Braćigovo, ont construit de grandes églises dans le centre urbain de l'intérieur de la Thrace, aussi bien que dans les alentours, en utilisant la technique de voûtes sous un toit commun ou à la coupole centrale légèrement proéminente. Des sculpteurs sur bois épirotes ont exécuté, par ailleurs, dans ces églises certaines des iconostases les plus remarquables.

47. Jean Cetiri et son fils Naoum ont peint, en 1806, l'église de Kozara, pas loin de Berat. Les frères Georges et Jean Cetiri doivent leur réputation aux fresques de Vanaj et de Karavasta. La tradition artistique de la famille fut perpétuée par le fils de Jean, Naoum, et son neveu Nicolas, qui ont réalisé les fresques des églises de Krutja, Toshkëz, Struma, Kadipashaj.

48. L'archimandrite Jean a, sans doute, joué un rôle important dans sa formation.

49. C'est un cas unique, dans le monde orthodoxe, de réunion à grande échelle des ateliers de peinture communs aux Grecs et aux Roumains. Le peintre Constantin a collaboré avec des artistes locaux qu'il a formés à l'iconographie orthodoxe. Il a adapté la tradition du style de l'école crétoise aux besoins locaux, marqués par le pittoresque et les éléments décoratifs de diverses formes et couleurs. Il a commencé en 1683, avec son collaborateur Jean, à peindre l'église de la Présentation de la Mère de Dieu, à Bucarest. Par la suite, on le retrouve, en 1684, peignant l'église de la Naissance de la Mère de Dieu, dans la région de Rimnicu-Vilcea, avec Jean et Panagiotis . En 1698, il peint l'église métropolitaine du Saint-Prodrome à Tîrgovişte, avec Jean, Joachim et Stano. En 1705, il peint, avec Rado et Fota l'église de Saint-Georges à Mogoşoaja . En 1707, avec deux collaborateurs, Andréa et Georges, il réalise la peinture du narthex extérieur du monastère de Kozija. En 1711-12, enfin, il supervise les travaux de peinture de l'église de l'Assomption de la Mère de Dieu à Polovraci, avec Andréa, Syméon, Istrati et Chranite. 


\section{RÉSUMÉS}

L'auteur propose une synthèse des architectures chrétiennes construites dans les Balkans, qu'il structure de manière transnationale afin de mieux surprendre les traits communs. Il retrace leurs histoire à travers deux grandes étapes chronologiques : celle des « résistances, médiations et adaptations, du XVI ${ }^{\mathrm{e}}$ au XVII ${ }^{\mathrm{e}}$ siècle, et celle de la «naissance des éclectismes et nouvelles spécificités ", aux XVIII ${ }^{\mathrm{e}}$ et XIX ${ }^{\mathrm{e}}$ siècles. Au long de ce découpage chronologique, l'article examine l'art chrétien - notamment les églises - en conjonction avec les grands courants artistiques de l'Europe du temps, leur circulation et l'influence exercée.

Organized as a national-crossover overview, this study of Christian architectures in the Balkans aims at defining their common features. Their history evolved in two phases: the "resistance, mediations and adaptations" ( $16^{\text {th }}-17^{\text {th }}$ c.), and the "birth of eclectisms and new specificities" (18 th $-19^{\text {th }}$ c.). The author examines Christian art -most specifically churches - in the light of broad artistic trends in Europe at the same time.

\section{AUTEUR}

\section{ALKIS PRÉPIS}

Université de Thrace, Komotini 